Review Article

\title{
Application of Computational Intelligence Algorithms in Radio Propagation: A Systematic Review and Metadata Analysis
}

\author{
Quadri Ramon Adebowale, ${ }^{1}$ Nasir Faruk, ${ }^{1,2}$ Kayode S. Adewole, ${ }^{3}$ Abubakar Abdulkarim, ${ }^{4}$ \\ Lukman A. Olawoyin, ${ }^{1}$ Abdulkarim A. Oloyede, ${ }^{1}$ Haruna Chiroma ${ }^{10},{ }^{5,6}$ Aliyu D. Usman, ${ }^{7}$ \\ and Carlos T. Calafate $\mathbb{D}^{8}$ \\ ${ }^{1}$ Department of Telecommunication Science, University of Ilorin, Ilorin, Nigeria \\ ${ }^{2}$ Department of Physics, Sule Lamido University, Kafin Hausa, Kano, Nigeria \\ ${ }^{3}$ Department of Computer Science, University of Ilorin, Ilorin, Nigeria \\ ${ }^{4}$ Department of Electrical Engineering, Ahmadu Bello University, Zaria, Nigeria \\ ${ }^{5}$ University of Hafr Al Batin, College of Computer Science and Engineering, Hafar Al-Batin, Saudi Arabia \\ ${ }^{6}$ Future Technology Research Center, National Yunlin University of Science and Technology, Douliu, Yunlin, Taiwan \\ ${ }^{7}$ Department of Electronics and Telecommunication Engineering, Ahmadu Bello University, Zaria, Nigeria \\ ${ }^{8}$ Department of Computer Engineering, Universitat Politècnica de València, Valencia, Spain
}

Correspondence should be addressed to Haruna Chiroma; chiromaharun@fcetgombe.edu.ng

Received 6 October 2020; Revised 29 January 2021; Accepted 10 February 2021; Published 24 February 2021

Academic Editor: Quanzhong Li

Copyright (C) 2021 Quadri Ramon Adebowale et al. This is an open access article distributed under the Creative Commons Attribution License, which permits unrestricted use, distribution, and reproduction in any medium, provided the original work is properly cited.

\begin{abstract}
The importance of wireless path loss prediction and interference minimization studies in various environments cannot be overemphasized. In fact, numerous researchers have done massive work on scrutinizing the effectiveness of existing path loss models for channel modeling. The difficulties experienced by the researchers determining or having the detailed information about the propagating environment prompted for the use of computational intelligence (CI) methods in the prediction of path loss. This paper presents a comprehensive and systematic literature review on the application of nature-inspired computational approaches in radio propagation analysis. In particular, we cover artificial neural networks (ANNs), fuzzy inference systems (FISs), swarm intelligence (SI), and other computational techniques. The main research trends and a general overview of the different research areas, open research issues, and future research directions are also presented in this paper. This review paper will serve as reference material for researchers in the field of channel modeling or radio propagation and in particular for research in path loss prediction.
\end{abstract}

\section{Introduction}

Since the birth of communications, mankind has always depended on the presence of a communications channel, even before the invention of modern technologies and techniques that replaced more traditional communication channels. The modern communication channel exists both in wired and wireless forms, and a plethora of applications and technologies are able to use both communication media effectively. The wireless form of communication techniques has enjoyed a wide acceptance due to its support for mobility. Wireless devices and applications are used for different purposes in various sectors including health, education, e-commerce, transportation, smart agriculture, disaster, social networks, and many others. Wireless systems infrastructure has also been deployed to support broadcasting, public safety communications, and cellular mobile telephony. In particular, the most widely deployed technology is the cellular mobile communications networks. Broadband Internet provision is of particular interest in meeting the sustainable development goals (SDGs), particularly, in the developing economies. Successful deployment of a wireless communications network would require optimum planning and proper design of the entire system, with more focus on its physical layer interface. The physical layer interface is the one that allows to interconnect users 
and the wired network, defining the quality of service (QoS) delivered by the providers and also the quality of experience (QoE) as perceived by the users, being that such features allow assessing how sophisticated and robust the physical layer interface really is. While designing the physical layer of wireless systems, many different parameters are brought forward for consideration, including QoS, coverage area, transmitted frequency, transmitted power, received power, and system budget. Thus, to determine how effective the values of these parameters can be when performing network planning in a particular topography, a suitable and well optimized radio frequency (RF) path loss propagation model must be applied.

Path loss represents the reduction in signal strength of the transmitted signal caused by large scale fading along the communication path. Hence, having accurate path loss models becomes essential during the deployment of wireless systems. Many different propagation models are available for different types of terrain, and their performances are location dependent and site specific. However, in order to obtain a dependable path loss model for a given area, a general model needs to be optimized and/or tuned. The optimized model can then be used by engineers to determine the correct values of parameters such as base station (BS) location, transmitter and receiver antenna height, down tilt angle, transmitted power, and frequency [1].

Path loss propagation models are grouped into four (i.e., empirical models, physical/analytical models, semiempirical models, and deterministic models) [2,3]. Each of these models contributes significantly to channel propagation modeling. The mentioned groups of the propagation model had contributed to the successful estimation of signal propagation loss for effective design of wireless communication systems. Among the numerous path loss models that exit, the empirical path loss propagation models have been widely used to predict the behavior of radio signals as they propagate throughout a particular environment and location. These models have enjoyed much attention from researchers because of their ease of use and simplicity, and the implementation of these empirical models requires less computational efforts. However, they failed to fully take into consideration the physical composition of the target environment, making them vulnerable to high prediction errors when applied in an environment different from which it was built for [4].

Their inability in getting detailed information about the propagating environment leads to the adoption of intelligent algorithms to predict path loss, including the artificial neural networks (ANNs) and fuzzy systems (FSs). These methods learn and adapt to any changes in the environment, thus providing a better prediction when compared with the traditional models. Nature-inspired computational methodologies, also known as computational intelligent (CI), such as the genetic algorithm (GA), particle swarm optimization (PSO), and ant colony (AC), provide a solution to the complex propagation environments where the traditional models failed [5]. In particular, these CI methods integrate neural networks, fuzzy logic, and other natural inspired algorithms to optimize the path loss, thus reducing the errors and improving the prediction accuracy.
Researchers have conducted various studies on the use of CI techniques for path loss predictions due to the need to implement robust wireless systems offering high performance. A comprehensive search was conducted to retrieve existing review papers providing a literature review of $\mathrm{CI}$ techniques applied to path loss prediction but only a single review article was found. The survey was conducted [6]. The review paper reported a comprehensive summary of CI techniques applications in wireless sensor networks (WSNs). The study examined all the use cases of CI, focusing attention on providing reports regarding the innovative use of CI techniques to solve WSN problems, such as design and deployment, security, localization, clustering, scheduling, optimal routing, data aggregation, and fusion. Also, the CI paradigms and challenges faced by WSNs are also identified, alongside with the solution provided by CI techniques in solving these challenges. Future research on the application of CI techniques, such as cross-layer design and parameter learning, is proposed as a future research area of $\mathrm{CI}$ in WSNs, as reported in the survey. However, the main issue about the previous survey is that it focuses mainly on WSNs without considering the path loss prediction problem. To the best of our knowledge, no survey has been conducted on the applications of $\mathrm{CI}$ in solving path loss prediction problems.

In this paper, we provide a clear perspective on this topic with a broad and in-depth review on the recent use of CI for path loss prediction. The computational methods considered in our review include artificial neural networks, fuzzy systems, swarm intelligence, and other forms of computer intelligence technique investigated by researchers. The motivation behind this research is to allow interested researchers to make use of this literature survey as a starting point for their own research, whereas expert readers can use the study to propose novel approaches for path loss prediction.

Thus, the contributions of this review paper can be summarized as follows:

(i) A taxonomy and descriptive literature review of computational intelligence model applications, covering the most recent peer-reviewed articles from top journals, conference proceedings, and edited books

(ii) Assessment and explorative analysis of the diverse issues and approaches adopted in the different works analyzed, highlighting their main advantages and flaws

(iii) Revealing open research issues and opportunities for future research in this area

The remaining sections of the paper are structured as follows. Section 2 presents some previous related surveys and reviews of applications of CI techniques for path loss predictions. Section 3 details the literature search method followed. A wide-ranging taxonomy of computational intelligence is then presented in Section 4. Section 5 discusses the pros and cons of the reviewed works. In Section 6, results obtained centered on the number of articles acquired from the research area are presented. Lastly, the main conclusions are drawn in Section 7 of the paper. 


\section{Review Methodology}

The research steps followed to review the prevailing works in the domain of CI for path loss prediction are presented in this section. Also, we detailed the selection process of the selected studies, which was done through a set of inclusion and exclusion criteria.

2.1. Literature Search and Data Sources. Our systematic review followed the guidelines provided in [7] on search strategy, and so we carefully selected the primary search terms for the purpose of determining the appropriate works for the study. In particular, the following terms are carefully applied to search for the relevant studies that had been conducted on CI for path loss prediction from relevant academic databases: "computational intelligence," "computational intelligence on path loss prediction," "neural network path loss prediction," "fuzzy logic path loss prediction," "genetic algorithm path loss prediction," "particle swarm optimization path loss prediction," "artificial immune systems path loss prediction," and so on. Table 1 shows the academic databases used for the literature search.

2.2. Study Selection Procedure. The study selection procedure was designed with caution to ensure that a comprehensive literature review is achieved. Articles were gathered from different academic databases that are relevant to this study; in particular, 957 articles were fetched and examined. This set was reduced to 321 based on a title check and 98 based on abstract. 98 articles were revised comprehensively to identify a final list of 46 articles based on the full contents of the papers; the full process is illustrated in Figure 1.

2.3. Studies Inclusion/Exclusion Criteria. In order to select the most relevant articles for the study, both inclusion and exclusion criteria were defined. To arrive at the final list, the main literature elements were selected by reading through the title, abstract, and full content of the selected papers. Thus, the inclusion and exclusion criteria applied in this present review are presented in Table 2.

Figure 2 shows the total number of selected articles from the target academic databases after applying all the preceding selection criteria.

\section{Taxonomy of Computational Intelligence Techniques}

The CI techniques can be broadly classified into five major categories [8]; these are depicted in Figure 3. The taxonomy presented in this paper is derived from all the reviewed literature used in this study. The categories are artificial neural networks (ANNs), fuzzy inference systems (FISs), evolutionary computing (EC), swarm intelligence (SI), and artificial immune systems (AISs).

3.1. Fuzzy Sets. This aspect of computational techniques was introduced and defined by means of a membership function
TABle 1: Databases used as data sources.

\begin{tabular}{lc}
\hline Academic database & URL address \\
\hline IEEE Explore & $\mathrm{http://ieeexplore.ieee.org/}$ \\
Springer & $\mathrm{http}: / /$ www.springer.com/ \\
Google Scholar & $\mathrm{https://scholar.google.com/}$ \\
Taylor \& Francis & $\mathrm{http} / /$ taylorandfrancis.com/ \\
ISI Web of Science & $\mathrm{https://apps.webofknowledge.com}$ \\
Science Direct & $\mathrm{http} / /$ www.sciencedirect.com/ \\
Scopus & $\mathrm{https://www.scopus.com/}$ \\
ACM Digital Library & $\mathrm{https://www.dl.acm.org/}$ \\
\hline
\end{tabular}

[10]. It can be applied to various practical applications as shown in $[11,12]$.

A fuzzy set makes its determination based on truth factors which take in the probabilities input in order to provide a definite output. In a fuzzy set $A$, an object $x$ may belong to this set with varying membership degrees in the range $[0,1]$, where 0 and 1 denote lack of membership and full membership, respectively [13].

A way of defining a fuzzy set $A$ is to provide its membership function, $\mu_{A}: x \longrightarrow[0,1]$. There are various membership functions, of which three are presented as follows [13-15]:

(i) Gaussian membership function (where $c$ and $\delta$ are parameters):

$$
\mu_{A}(x, c, \delta)=\exp \left(-\frac{(x-c)^{2}}{2 \delta^{2}}\right) .
$$

Parameter $c$ specifies the center of a function, and parameter $\delta$ determines its dispersion.

(ii) Trapezoidal membership function (where $p \leq q \leq$ $r \leq s$ are parameters):

$$
\mu_{A}(x ; p, q, r, s)= \begin{cases}0, & x \leq p, \\ \frac{x-p}{q-p}, & p<x \leq q, \\ 1, & q<x \leq r, \\ \frac{s-s}{s-r}, & r<x \leq s, \\ 0, & x>s .\end{cases}
$$

A special case of a trapezoidal function (for $q=r$ ) is a triangular function.

(iii) Singleton (where $x_{0}$ is a parameter):

$$
\begin{aligned}
\mu_{A}\left(x ; x_{0}\right) & =\delta_{x}, \\
x_{0} & = \begin{cases}1, & x=x_{0}, \\
0, & x \neq x_{0} .\end{cases}
\end{aligned}
$$

A fuzzy inference system (FIS) model is based on fuzzy set theory, fuzzy "if/then" rules, and fuzzy 

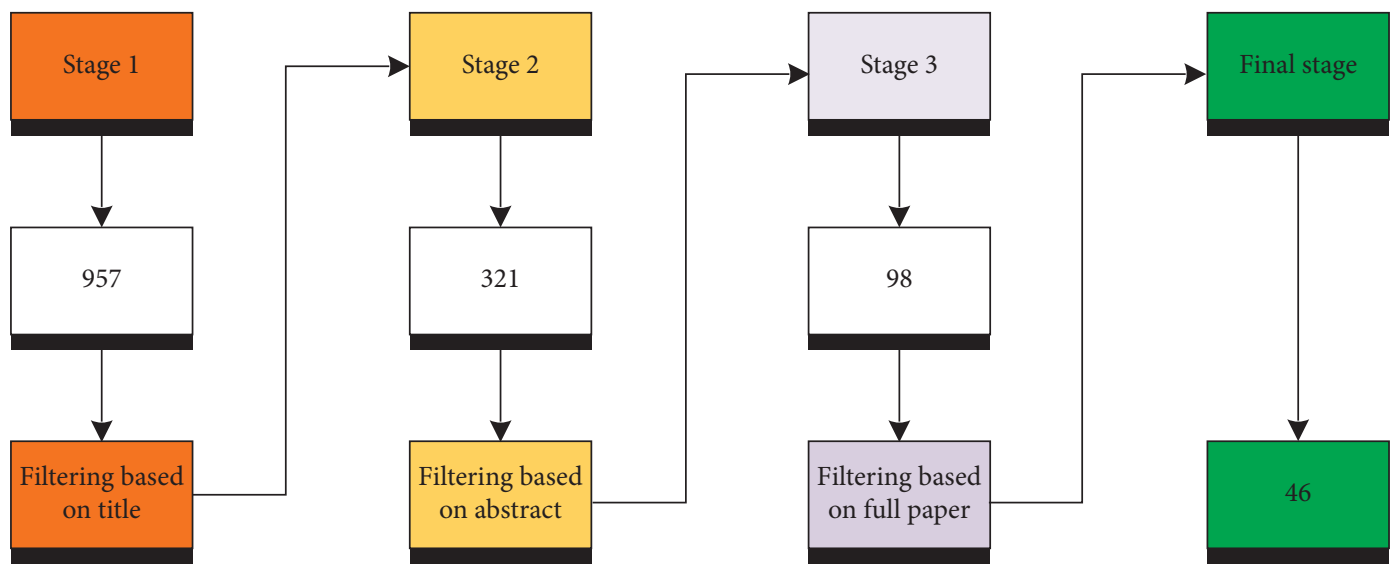

FIGURE 1: Study selection procedure.

TABLe 2: Selection criteria of the study.

Inclusion criteria

Exclusion criteria

The literature survey focuses on path loss prediction only

The review process focuses on the application of CI techniques to path loss prediction only

The review concentrated on published peer-reviewed papers only

The study considers the literature published in reputable The study does not consider the literature published in the books, abstracts, journals and conferences

The study considered articles that are written in Englis only
The literature survey does not consider other forms of prediction

The review does not concentrate on the application of CI techniques on other forms of research besides path loss prediction

The review did not consider nonpeer reviewed articles such as descriptions, technical reports, and workshops

keynotes, or editorials

rticles that were written in other languages apart from English

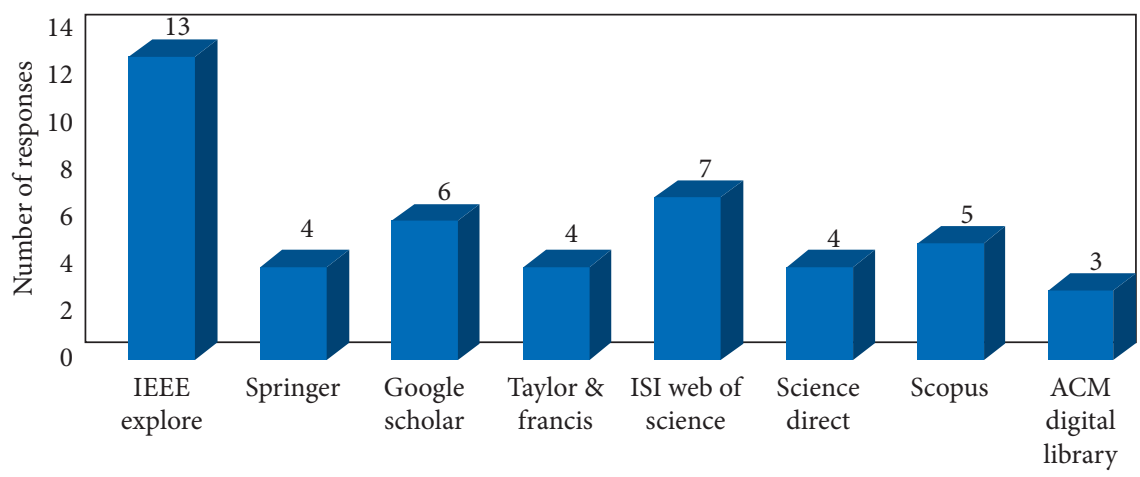

FIgURE 2: Total number of articles acquired from the queried search databases.

reasoning as shown in Figure 4. The FIS approximate functions are based on a rule base, a database, and a reasoning mechanism. The adaptive neuro-fuzzy inference system (ANFIS) is a class of adaptive networks that are functionally equivalent to FIS. An adaptive network is a multilayer feed forward network where each node performs a particular function on incoming signals. ANFIS has five layers, as shown in Figure 5.

The description of the structure above is done with a first-order sugeno because the output is a crisp value. A sugeno-based ANFIS has a rule of the form [17].
Rule 1:

If $x$ is $A_{1}$ and $y$ is $B_{1}$, then $f_{1}=p_{1} x+q_{1} y+r_{1}$.

Rule 2:

If $x$ is $A_{2}$ and $y$ is $B_{2}$, then $f_{2}=p_{2} x+q_{2} y+r_{2}$.

3.1.1. Layer 1. A node in this layer is adaptable and is given as follows:

$$
L_{i}^{1}=\mu A_{i}(x), \quad i=1,2 .
$$




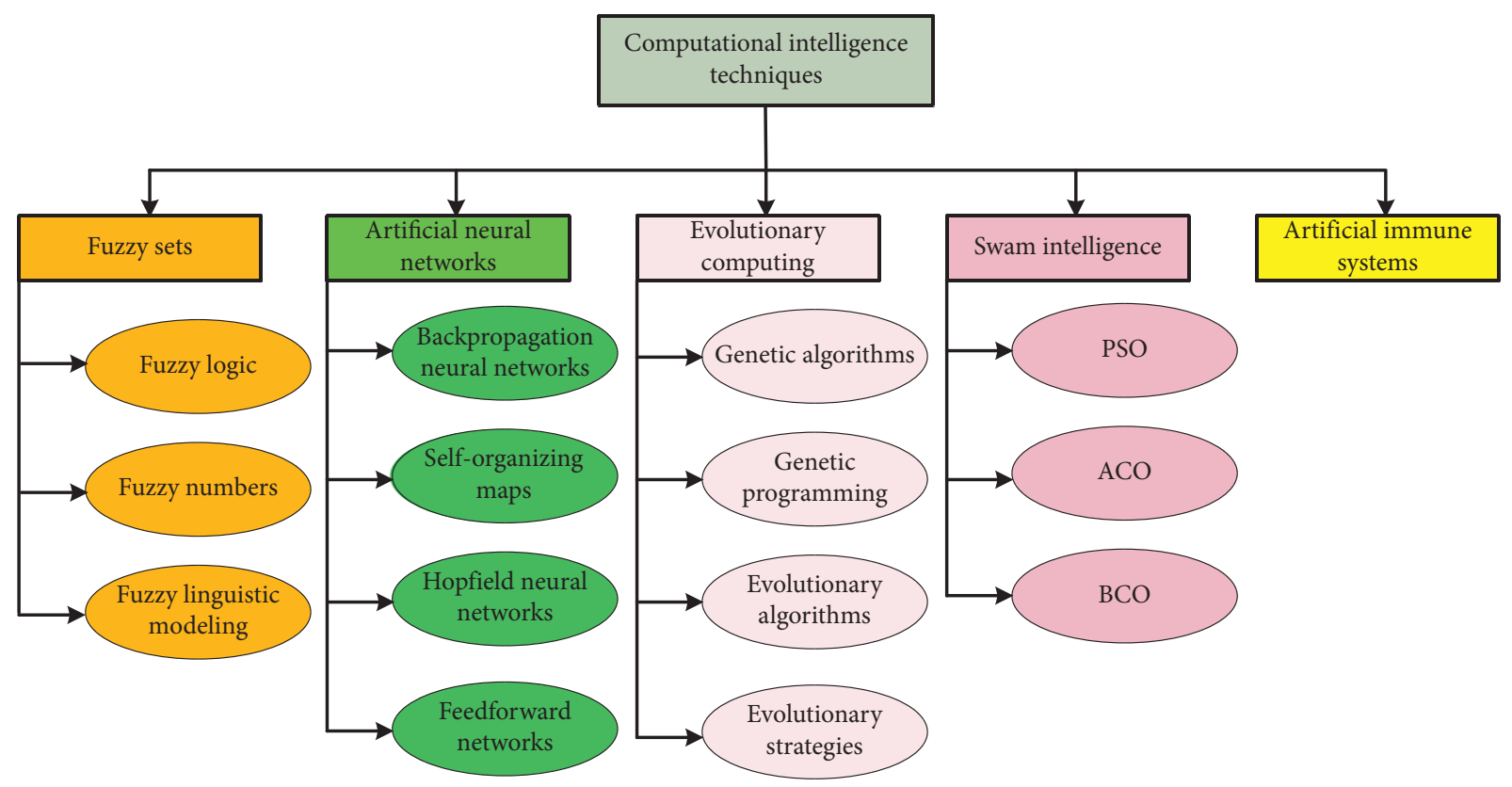

Figure 3: Taxonomy of computational intelligence techniques [9].

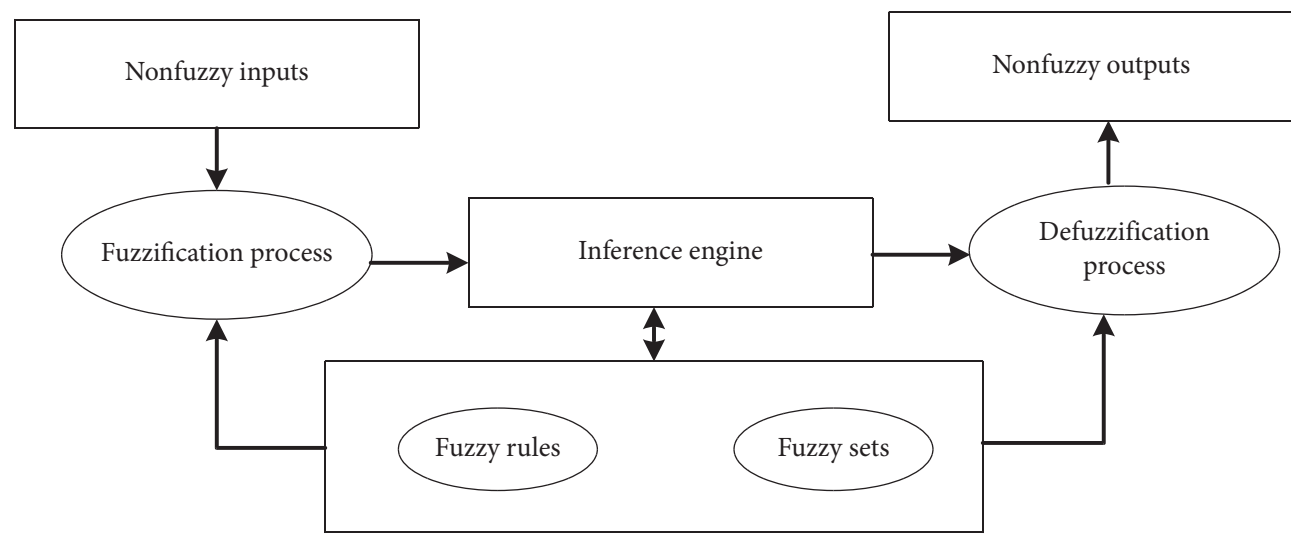

FIGURE 4: Block diagram of a fuzzy inference system.

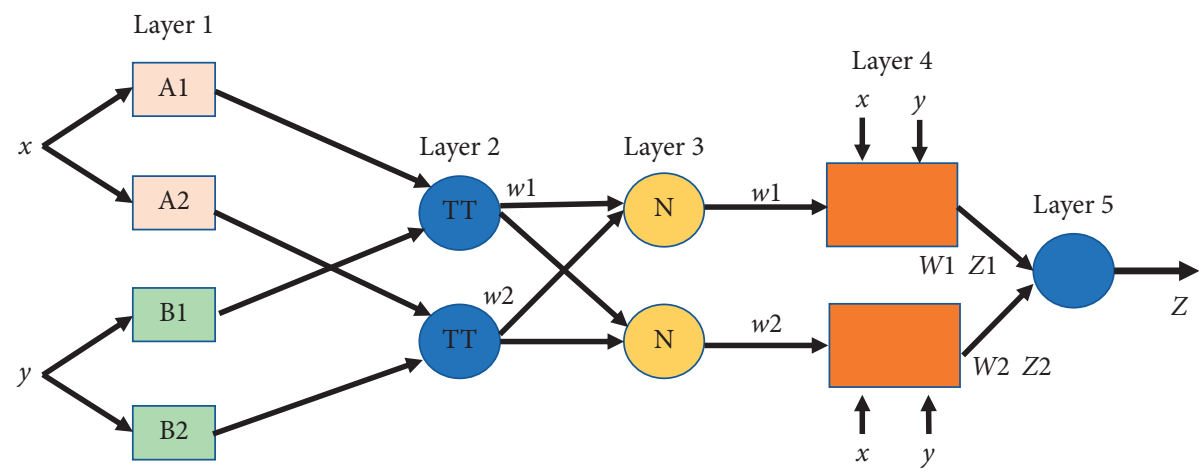

FIgURE 5: The ANFIS structure [16]. 
The input to the $i$ th node is $x, A_{i}$ is a changeable language relating to this node, and the MF of $A_{i}$ is $\mu A_{i}(x)$ which is taken normally as follows:

$$
\mu A_{i}(x)=\frac{1}{1+\left[\left(\left(x-f_{i}\right) / d_{i}\right)^{2}\right] e_{i}},
$$

where $\left\{d_{i}, e_{i}, f_{i}\right\}$ is the antecedent variables set. Equation (7) is a representation of the generalized bell MF.

The membership function decides the mapping of each point in the input space by assigning a membership value in an interval of 0 and 1 . The input (antecedent) variables are initially generated by the trial and error method. These variables are therefore adjusted through the learning capability of the NN which enables the errors reduction to be easier and at the same time optimizing the output (consequent) variables [17].

3.1.2. Layer 2. This layer is made up of the stable nodes which solve the firing power $w_{i}$ also known as the synaptic weight of a rule. The output of each node is the multiplication of the incoming signals given by the following:

$$
L_{i}^{2}=w_{i}=\mu A_{i}(x) \times \mu B_{i}(y), \quad i=1,2 .
$$

3.1.3. Layer 3. The output of each node in this layer is constant which is given by the following:

$$
L_{i}^{3}=\overline{w_{i}}=\frac{w_{i}}{\sum w_{i}}, \quad i=1,2
$$

3.1.4. Layer 4. The changeable output of this layer is given by the following:

$$
L_{i}^{4}=\overline{w_{i}} f_{i}=\overline{w_{i}}\left(p_{i} x+q_{i} y+r_{i}\right), \quad i=1,2,
$$

$\left\{p_{i}, q_{i}\right.$ and $\left.r_{i}\right\}$ is the consequent variables set and they are computed using the least squares estimates method.

3.1.5. Layer 5. The addition of all the input signals from layer 4 is the output of this layer and is given by the following:

$$
L_{i}^{5}=f=\sum_{i=1}^{2} \bar{w}_{i} f_{i}=\frac{\sum w_{i} f_{i}}{\sum w_{i}} .
$$

The ANFIS optimization combines both the least square errors estimate and backpropagation algorithms which establishes the output and input parameters, respectively, until the training is completed. It is a statistical approach employed in determining a line of best fit through the minimization of the sum of squares of a mathematical function.

Equation (11) can be rewritten as follows:

$$
\begin{aligned}
f & =z_{p}^{k}=\frac{w_{1}}{w_{1}+w_{2}} f_{1}+\frac{w_{2}}{w_{1}+w_{2}} f_{2}, \\
z_{p}^{k} & =\overline{w_{1}} f_{1}+\overline{w_{2}} f_{2} \\
& =\sum_{i=1}^{2} \overline{w_{i}} f_{i}=\overline{w_{1}}\left(p_{1} x\right)+\overline{w_{1}}\left(q_{1} y\right)+\overline{w_{1}}\left(r_{1}\right)+\overline{w_{2}}\left(p_{2} x\right)+\overline{w_{2}}\left(q_{2} y\right)+\overline{w_{2}}\left(r_{2}\right),
\end{aligned}
$$

$$
f=z_{p}^{k} \text { is the overall predicted output. }
$$

Various nature-inspired algorithms have been proposed to improve the prediction of path losses and to aid in successful design and implementation of wireless systems. For instance, Dalkili et al. [18] proposed the use of fuzzy logic and developed a new algorithm centered on an adaptive neuro-fuzzy inference system (ANFIS) for the tuning of the path loss model when estimating the propagation loss in a particular urban terrain. The literature also introduced the use of a statistical-based comparison using the Bertoni-Walfisch model for a proper performance evaluation of any newly developed algorithm. The mean squared error used as the performance indicator between the developed the ANFIS model and the Bertoni-Walfisch model indicated less predicted errors from the ANFIS model than for the latter. It was indicated by the lowest mean square error value. The ANFIS model reveals the minimum MSE value compared with the Bertoni-Walfisch model. The study only focuses on a specific city of Turkey and on the $900 \mathrm{MHz}$ frequency band.

In [19], the authors proposed the use of a multilayer fuzzy logic system (MLFS) for path loss prediction in different forest densities, at a frequency of $1.8 \mathrm{GHz}$, and with a base station antenna height ranging from 3 to $5 \mathrm{~m}$ above the ground and having the receiving antenna $1.8 \mathrm{~m}$ above the ground. The performance indicated that the developed fuzzy model has better accuracy in path loss prediction than that of the empirical models, meaning that it will be more suitable for local wireless networks and microcell design for wireless mobile communication systems in forests.

Gupta et al. [20] reported in the literature the use of fuzzy logic to propose a better method to predict path loss for the proper location of base stations in wireless mobile communication systems. A fine-tuning HATA model was used for the analysis in which a unique mean path loss exponent 
( $n$ ) was assigned to each tested propagation area. The results proved that, with the HATA model, the prediction path loss increases at the rate of $3.426 \mathrm{~dB}$; a comparison of the measured model with the HATA model signifies a difference of $0.536 \mathrm{~dB}$. The path loss slope was plotted for each terrain using linear regression. In [21], the researchers preferred the use of BPSK modulated signals to obtain the path loss using the HATA model acquired with the help of the Okumura curve for urban, suburban, and rural terrains. The estimated predicted values of the path loss from the HATA model are derived from the adjustment made on parameters like antenna height, and distances were given as an input to the fuzzy system for the determination of the membership value of the estimated path loss for urban, suburban, and rural regions. The data derived from the path loss after the feeding of the fuzzy input system are represented with a linear regression using fuzzy logic. The obtained results show a maximum predicted loss in urban environments and increases with distance at an average rate of $10 \mathrm{~dB}$ per decade. The proposed fuzzy technique demonstrated a better signal transmission by determining the path loss accurately. In [22], the article reported the introduction of the fuzzy approach on the prediction of path loss. A set of fuzzy sets were considered in terms of free space, low foliage terrain, high foliage terrain, flat terrain, and country side terrain, where the path loss exponent was applied for the different propagation profiles. Mamdani fuzzy inference was used to derive the path loss exponent $(n)$ for each profile considered. The results in the literature revealed a path loss exponent $(n)$ of 2.2 for clear areas, while light vegetation, small towns, and heavy vegetation scenarios showed values of 3.3, 4.1, and 4.7, respectively. It was centered on low rooftop buildings. In [23], the authors proposed the use of K-means clustering and fuzzy logic for the minimization of prediction path loss error. The research studied an urban area of Thailand's Nonthaburi Province, where the training area used consisted of man-made buildings with variable heights and dense and large vegetation, and the study focused on both the 900 and $1800 \mathrm{MHz}$ frequency bands. The path loss prediction between the transmitter and the receiver associated with the empirical prediction models was carried out using MAT$\mathrm{LAB}$. The results show that the prediction path loss of the newly developed k-mean fuzzy scheme was only $2.67 \%$ in comparison with the test-drive measurement, for which it reveals the lowest error alongside the other compared models. Supachai and Pisit in [24] proposed the use of new upper- and lower-bound models for the line-of-sight prediction of path loss in microwave systems in the frequency bands of $3.35,8.45$, and $15.75 \mathrm{GHz}$, using fuzzy linear regression (FLR) for which the spread of the upper- and lowerbound of the fuzzy approach is dependent on the maximum and minimum value of the sample path loss data, while the width of the upper and lower regression values used is fixed. The developed model was compared with the conventional path loss models, and the FLR indicates its improvement in accuracy and, as such, it is suitable for the design of the fourth generation multimedia mobile communication systems exhibiting microwave bands frequency. Salman et al. [25] adopted the neuro-fuzzy (NF) model for the prediction of path loss in the Ilorin metropolitan area focusing on the VHF band. Four different routes were used during the measurement to obtain the received signal strength using the NTA Ilorin transmitter, which operates on the frequency of 203.25 MHz; the developed model was alongside compared with widely used empirical path loss models (Hata, Egli, Ecc33, and COST 231). The performance was measured using the root mean square error (RMSE) across all the routes visited. The results indicated an average RMSE of $5.23 \mathrm{~dB}$, $9.487 \mathrm{~dB}, 18.696 \mathrm{~dB}$, and $27.890 \mathrm{~dB}$, respectively, for the neuro fuzzy, ECC-33, HATA, COST 231, and Egli models. The newly developed model achieved more accuracy and improvement on the predictions of path loss. The study is limited to NTA with four routes. Jafri et al. [26] conducted a study on the use of a neural network (NN) model combined with fuzzy logic (FL) to estimate the interference path loss on Airbus 319 and 320 airplanes. The interference patterns were classified based on windows, aircraft structure, communication/navigation systems, and location of the doors. The modeled results were compared with the measured data where the modeled algorithm revealed an improvement during the comparison. However, the research is limited to aircraft-related prediction. Gupta et al. [20] proposed the prediction of path loss for the current point of a base station in a cellular mobile communication using fuzzy logic (FL). Various media were used as the propagation environment that are defined as fuzzy sets such as flat area terrain, light vegetation, free space, heavy vegetation terrain, and village terrain in the suburban city Mehuwala, Dehradun, for its CDMA-based wireless system. Path loss exponent ( $n$ ) was assigned to each environment that is established by means of an experimental decision. The fuzzy logic was used to determine the path loss exponent $(n)$ of which the clear area, light vegetation, small town, and heavy vegetation scenarios revealed values of $2.4,3.9,4.2$, and 4.9 , respectively, as shown in Table 3.

Danladi and Vasira [28] proposed the use of fuzzy logic and spline interpolation to modify the Hata model when estimating the propagation loss from $500 \mathrm{MHz}$ to $1500 \mathrm{MHz}$, for BTS and MS distances ranging from $1 \mathrm{~km}$ to $20 \mathrm{~km}$, a base transceiver station height from $30 \mathrm{~m}$ to $200 \mathrm{~m}$, and a mobile station height from $1 \mathrm{~m}$ to $10 \mathrm{~m}$, within Yola, Adamawa State, Nigeria. The performance of the modified model was tested, obtaining mean absolute errors of $1.55 \mathrm{~dB}$ and $0.4 \mathrm{~dB}$. The fuzzy logic/spline interpolation model path loss is reduced by $1.94 \mathrm{~dB}$ in the studied terrain as reported in the literature, which makes it suitable for path loss prediction for next generation wireless networks, especially in Yola. In [18], the use of fuzzy logic to have a new algorithm based on ANFIS for tuning the path loss model was proposed. The adaptive-network-based fuzzy interference system (ANBFIS) is an algorithm introduced in this study for path loss prediction in a particular urban environment. The study also introduced a statistical-based comparison for proper evaluation with the Bertoni-Walfisch model. Results show less error with ANBFIS prediction than with the Bertoni-Walfisch model. The study is limited to the GSM $900 \mathrm{MHz}$ band and a specific city. In [27], a propagation path loss algorithm with the use 
TABLE 3: Summary of fuzzy logic computational process.

\begin{tabular}{|c|c|c|}
\hline Authors & Aim & Methods \\
\hline Dalkili et al. [18] & To have a new algorithm-based ANFIS for tuning the path loss model & ANFIS \\
\hline Supachai et al. [19] & To propose a multilayer fuzzy logic system (MLFS) for path loss prediction & $\begin{array}{l}\text { Multilayer fuzzy logic system } \\
\text { (MLFS) }\end{array}$ \\
\hline Gupta et al. [20] & To propose a better method to predict path loss & \\
\hline Sanu et al. [21] & To proffer the use of a BPSK modulated signal to obtain the path loss & $\begin{array}{l}\text { Fuzzy system + linear } \\
\text { regression }\end{array}$ \\
\hline Sumit et al. [22] & To introduce a fuzzy approach on the prediction of path loss & Mamdani fuzzy inference \\
\hline $\begin{array}{l}\text { Bhupuak and } \\
\text { Tooprakai [23] }\end{array}$ & $\begin{array}{c}\text { The use of K-means clustering and fuzzy logic for the minimization of prediction } \\
\text { path loss error }\end{array}$ & K-means and fuzzy logic \\
\hline Supachai and Pisit [24] & $\begin{array}{c}\text { The use of new upper- and lower-bound models for the line-of-sight prediction of } \\
\text { path loss in microwave systems }\end{array}$ & Fuzzy linear regression \\
\hline Salman et al. [25] & Applied neuro-fuzzy model for & ANFIS \\
\hline Gupta et al. [20] & $\begin{array}{l}\text { Path loss prediction for current point of base station in a cellular mobile } \\
\text { communications }\end{array}$ & Fuzzy logic \\
\hline $\begin{array}{l}\text { Surajudeen-Bakinde } \\
\text { et al. [27] }\end{array}$ & Test ANFIS for path loss prediction & ANFIS \\
\hline $\begin{array}{l}\text { Danladi and Vasira } \\
\text { [28] }\end{array}$ & Uses fuzzy logic and spline interpolation to modify the Hata model & Fuzzy logic \\
\hline Shoewu et al. [29] & $\begin{array}{l}\text { To develop a new propagation path loss model for different terrains in Lagos in the } \\
\qquad 900 \mathrm{MHz} \text { and } 1800 \mathrm{MHz} \text { frequency bands }\end{array}$ & Fuzzy logic \\
\hline
\end{tabular}

of one classification out of fuzzy set techniques was proposed, and data set was generated using a multitransmitter (i.e., three different transmitters) radiating radio signals in the VHF bands. The prediction model was developed within an urban terrain in Ilorin, Kwara State, Nigeria. A five-layer optimized approach ANBFIS network was used for the training of the measured data centered on the backpropagation gradient descent algorithm. The performance of the ANBFIS developed model was tested and achieved an error reduction for the correlation coefficient (R), RMSE, and standard deviation error (SDE), with values of $0.92 \mathrm{~dB}, 4.47 \mathrm{~dB}$, and $4.45 \mathrm{~dB}$, respectively. The developed algorithm achieves a better estimation accuracy while remaining simple. Reference [29] relied on a fuzzy logic algorithm to estimate propagation path loss for urban, suburban, exurban, dense-urban, microurban, and periurban terrains in the Lagos metropolitan environment, for both the $900 \mathrm{MHz}$ and the $1800 \mathrm{MHz}$ frequency bands. The results revealed that the mean path loss in these different environments is higher in the $900 \mathrm{MHz}$ band in comparison to the $1800 \mathrm{MHz}$ band. Furthermore, the urban terrain achieves the highest value for the constant offset ( $60 \mathrm{~dB}$ for the $900 \mathrm{MHz}$ band), and the exurban terrain shows a constant offset of $64 \mathrm{~dB}$ in the $1800 \mathrm{MHz}$ band. In general, the literature focuses on the 900 and $1800 \mathrm{MHz}$ frequency spectrum. Reference [30] performed experimental investigation on heuristic, geospatial, and empirical models after the use of the artificial neural network (ANN) method, adaptive neuro-fuzzy inference system (ANFIS), and Kriging technique for the development of the compared models for path loss prediction in the VHF and UHF frequency bands. The models were compared with reference to its RMSE value in which it was reported that the root mean square errors of all aforementioned compared models are considered acceptable. The ANN and ANFIS developed models produced the lowest prediction errors, in which the empirical models revealed the lowest standard deviation error (SDE). This project focuses on VHF and UHF frequency bands.

3.2. Artificial Neural Networks. The artificial neural network (ANN) was derived from the human brain, consisting of the large parallel interconnection of a large number of neurons, resembling the human nerve system. Its popularity can be traced to the late 1800 s, when scientific attempts to study the human brain were made. In 1890, William James published the very first scientific article detailing brain activity patterns. The first mathematical computational model of neurons was created by Walter and McCulloch, and it is still used in artificial neural networks as of [31]. The first artificial neural network was created in the year 1951 [32].

ANN is an artificial intelligence technique which can effectively be used for the development of path loss models, providing a solution for prediction problems. A neural network has the competence to learn, and it has no need of an explicit knowledge of the input and output process relationship [33]. Some researchers [3, 8, 33] have performed several studies on ANN to develop propagation models. Therefore, it can be useful in the development of path loss for better prediction of received signal strength and interference analysis. ANN sometimes consists of an input, hidden layers, and output layer which can be connected partially or fully to the NN in the next layer [8]. Several works have proposed the use of artificial neural networks for the tuning of propagation models and also the development of ANNbased algorithms for the prediction of path losses. For example, reference [34] conducted a study on macrocell pathloss prediction using artificial neural networks; in their work, an IS-95 pilot signal was utilized alongside a CDMA mobile network to collect measurement data in a rural environment of Australia. Factors such as training time, 
prediction accuracy, and generalization properties were considered during the evaluation, being backpropagation training algorithms such as gradient descent and Levenberg-Marquardt also evaluated. The prediction results were compared with the ITU-R P.1546 and the OkumuraHata model, in which the statistical analysis revealed that the noncomplex ANN model performed very well in terms of prediction time, complexity, and accuracy. In particular, it shows average results of $22 \mathrm{~dB}$ for the maximum error, a mean error of $0 \mathrm{~dB}$, and a standard deviation of $7 \mathrm{~dB}$. Also, a result comparison between the backpropagation models, gradient descent, Levenberg-Marquardt, and neural network revealed that the training time decreases from 150,000 to 10 iterations, while the prediction accuracy was maintained as shown in Figure 6.

3.2.1. Operation of ANN Neuron. The fundamental element of ANN is the neuron. Let $N$ be the number of inputs with $k$ neuron and the single output $y$ :

$$
\begin{aligned}
v_{k} & =\sum_{i=1}^{m} x_{i} w_{k i}+b_{i}, \\
y_{k} & =\varphi\left(\sum_{i=1}^{m} x_{i} w_{k i}+b_{i}\right), \\
y_{k} & =\varphi\left(v_{k}\right), \\
\varphi & =\frac{1}{1+e^{-a v_{k}}},
\end{aligned}
$$

where $\varphi=$ activation function.

3.2.2. Activation Functions. The activation function is denoted by $\varphi(v)$, which defines the output of a neuron in terms of the induced local field's $v$.
(1) Logistic Function. This is a form of sigmoidal nonlinearity function that satisfies the differentiability condition used in the multilayer perceptron of a neural network. It is generally expressed by the following:

$$
\varphi_{j}\left(v_{j(n)}\right)=\frac{1}{1+\exp \left(-a v_{j}(n)\right)}, \quad a>0,
$$

where $v_{j}(n)$ represents the induced local field of neuron $j$. According the nonlinearity, the output lies between the ranges $0 \leq y_{j} \leq 1$. The derivative of equation (14) with respect to $v_{j}(n)$ resulted as follows:

$$
\varphi_{j}^{\prime}\left(v_{j(n)}\right)=\frac{a \exp \left(-a v_{j}(n)\right)}{\left[1+\exp \left(-a v_{j}(n)\right)\right]^{2}},
$$

with $y_{j}(n)=\varphi_{j}\left(v_{j(n)}\right)$, and the exponential term $\exp \left(a v_{j}\right.$ (n)) can be eliminated from equation (15), and the new derivative $\varphi_{j}^{\prime}\left(v_{j(n)}\right)$ is expressed as

$$
\varphi_{j}^{\prime}\left(v_{j(n)}\right)=a y_{j}(n)\left[1-y_{j}(n)\right] .
$$

Considering a neuron $j$ that is located in the output layer, $y_{j}(n)=o_{j}(n)$. Hence, we may express the local gradient for neuron $j$ as follows:

$$
\begin{aligned}
\delta_{j}(n) & =e_{j}(n) \varphi_{j}^{\prime}\left(v_{j(n)}\right), \\
\text { Neuron } j \text { is an output node } & =a\left[d_{j}(n)-o_{j}(n)\right] o_{j}(n)\left[1-o_{j}(n)\right],
\end{aligned}
$$

where $o_{j}(n)$ is the function signal at the output of neuron $j$ and $d_{j}(n)$ is the desired response for it. For an arbitrary hidden neuron $j$, we may express the local gradient as follows:

$$
\delta_{j}(n)=\varphi_{j}^{\prime}\left(v_{j(n)}\right) \sum_{k} \delta_{k}(n) w_{k j}(n)=a y_{j}(n)\left[1-y_{j}(n)\right] \sum_{k} \delta_{k}(n) w_{k j}(n), \quad \text { neuron } j \text { is hidden. }
$$

(2) Hyperbolic Tangent Function. This type of function is also used as a form of sigmoidal nonlinearity which is defined in its most general form by the following:

$$
\varphi_{j}^{\prime}\left(v_{j(n)}\right) a \tanh \left(b v_{j}(n)\right),
$$

where $a$ and $b$ are positive constants. In the real sense, the hyperbolic tangent function is another logistic function that is rescaled and biased. Its derivative with respect to $v_{j(n)}$ is given by the following:

$$
\begin{aligned}
\varphi_{j}^{\prime}\left(v_{j(n)}\right) & =a b \operatorname{sech}^{2}\left(b v_{j}(n)\right) \\
& =a b\left(1-\tanh ^{2}\left(b v_{j}(n)\right)\right) \\
& =\frac{b}{a}\left[a-y_{j}(n)\right]\left[a+y_{j}(n)\right] .
\end{aligned}
$$

For a neuron $j$ located in the output layer, the local gradient is 


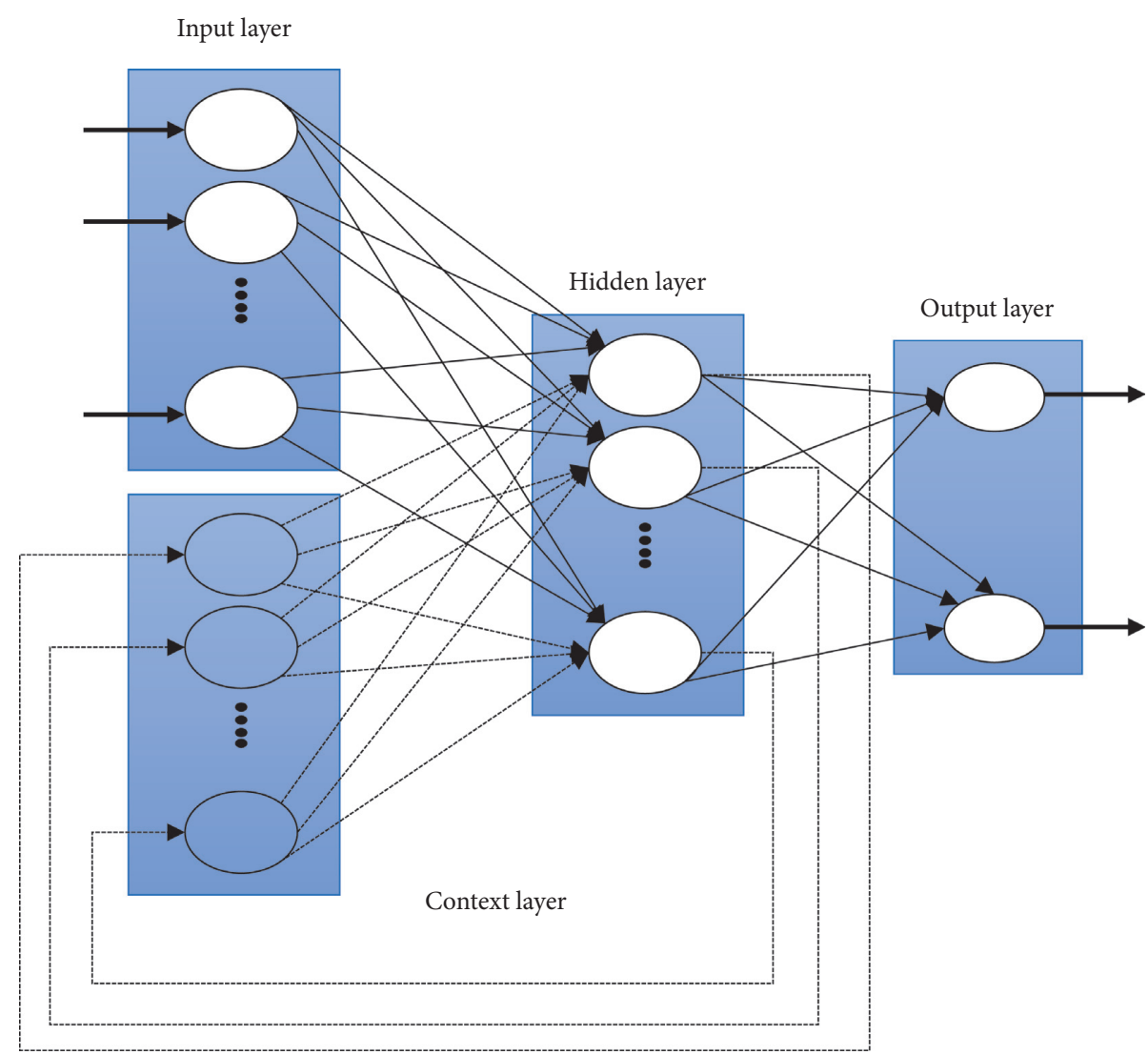

FIgURe 6: Popular neural network architecture.

$$
\begin{aligned}
\delta_{j}(n) & =e_{j}(n) \varphi_{j}^{\prime}\left(v_{j}(n)\right) \\
& =\frac{b}{a}\left[d_{j}(n)-o_{j}(n)\right]\left[a-o_{j}(n)\right]\left[a+o_{j}(n)\right] .
\end{aligned}
$$

For a neuron $j$ in a hidden layer, we have

$$
\delta_{j}(n)=\varphi_{j}^{\prime}\left(v_{j}(n)\right) \sum_{k} \delta_{k}(n) w_{k j}(n)=\frac{b}{a}\left[a-y_{j}(n)\right]\left[a+y_{j}(n)\right] \sum_{k} \delta_{k}(n) w_{k j}(n) .
$$

In [35], feed forward neural networks were used to predict the propagation path loss in urban and suburban environments; the study also reported an error correction model achieved from the combination of a theoretical deterministic model and the neural network. The performance of the developed neural models was tested alongside the measured path loss values obtained from the campaign, being based on absolute MSE, SD, and RMS between predicted and measured values. It was demonstrated that the proposed neural network models prove greater accuracy since the environmental factors are subtly considered, and so the ANN model can easily adapt to the environment characteristics. Similarly, in [36], an alternative neural network algorithm was proposed for the prediction of propagation path loss in urban environments. In the work, detailed environmental characteristics were used in the inputs to the model. The obtained results are compared with the results retrieved from the ray-tracing model, and it achieves a better accuracy either for a uniform or nonuniform distribution of the terrain. The trained data used provided better performance if nonuniform built-up areas were examined.

In [37], multilayer perceptron ANN based on backpropagation was used to develop an ultrawide band propagation channel model in a mine environment. The goal was to predict the change in path loss fading as a function of distance (i.e., 1 to 10 meters) and frequency $(3 \mathrm{GHz}$ to $10 \mathrm{GHz}$ ). The developed model was compared with the experimental measured values and was found to have achieved greater predicted accuracy. In [38], a multilayer perceptron (MLP) and a radial basis function (RBF) were employed to model an UWB channel in an underground harsh environment. The training of the ANNs relied on $5 \%$ 
of the data as learning samples (8000 points out of 160010 points). Authors compared both developed ANN approaches, and the results revealed that the RBF ANN achieved a lower error rate $(\mathrm{MSE}=0.0844 \mathrm{~dB}$ ) when compared with MLP ANN $((\mathrm{MSE}=1.7618 \mathrm{~dB})$, evidencing a higher accuracy in channel modeling. Authors in [39] proposed a propagation path loss model using an artificial neural network in an urban environment with the application of adaptive evolutionary algorithms. Two different ANN design cases were compared with the results from the ray-tracing model. Results indicated that the proposed model prediction achieves a satisfactory accuracy compared with the output from the ray-tracing model in the same environment. The authors in [40] relied on the Levenberg-Marquardt algorithm as one of the ANN models to predict propagation path loss of an FM radio station. The results obtained from the Levenberg-Marquardt algorithm were compared with ITU-R 1546 and Epstein-Peterson models. Results revealed that their approach achieved a better performance than both the theoretical and empirical (ITU-R 1546 and Epstein-Peterson) propagation models in terms of prediction time, complexity, and prediction accuracy. In particular, the RMSE value using the neural network model of Levenberg-Marquardt $(9.57 \mathrm{~dB})$ was lower than the RMSE achieved with the ITU-R 1546 and Epstein-Peterson propagation models $(10.26 \mathrm{~dB})$. Table 4 provides the summary of artificial neural networks contributions.

Authors in [41] proposed the use of a heuristic approach, such as ANN, to develop a statistical path loss model for the digital terrestrial television (DTT) coverage of the national broadcasting network (NBN). Indoor measurements were conducted at 28 residential areas using live broadcast at $677 \mathrm{MHz}$. The penetration loss and path loss in four types of residential areas (Class A, B, C, and D) were investigated, being indoor losses measured using fixed and portable indoor antennas at $1.5 \mathrm{~m}$. The four residential indoor path loss models developed would only work for similar residential environments in these four categories after further calibration to improve accuracy using a heuristic approach. In [42], the feed forward MLP network was applied to modify the Okumura-Hata model in the $890-960 \mathrm{MHz}$ frequency band. A comparison between the measured data and the theoretical values obtained with the model showed that the prediction model applies environmental conditions for the respective terrain where training was done. Subsequently, it improves prediction accuracy, with an error of $0.07 \mathrm{~dB}$. However, rainy weather condition is not considered as part of the environmental conditions in the work. Authors in [43] proposed the development of an ANN model for path loss estimation in TV transmission. The prediction model lays the basis on field strength measurements, which is then replaced with measurements from Longley-Rice model simulations. An evaluation of predicted results shows that the proposed model exhibits more accuracy and adaptability compared with familiar empirical models, such as Egli and Free-Space path loss. In [44], an ANN was used to develop a model for estimating path loss in the Great Tripoli area considering five different area types (dense urban, urban, dense suburban, suburban, and rural) in the 900,1800 , and $2100 \mathrm{MHz}$ frequency bands. The study relies on real RSS measurements to train and evaluate the model. The results of the developed ANN model were compared with the real values. The RMSE for the ANN varies from 3.0 to 6.7 depending on the area type and frequency of operation, achieving values that are better than those obtained with the Hata model. The comparison results show that the proposed model recorded a higher prediction accuracy when compared with real measurements. Also in [33], an ANN was used to develop a path loss propagation models that considered atmospheric parameters, relative humidity, and dew point, as inputs parameters. The models were used in estimating the reception power of GSM signals. An MLP network architecture and the weight and bias value were used in the development of the models. The performance of the proposed models was tested and found to be efficient with a mean squared error (MSE) of 0.056. Eichie et al. in [45] developed an ANN-based path loss model for signal quality estimation in rural and urban areas. They relied on a feedforward network topology and the Matlab Network Toolbox learning algorithm; specifically, they used the Levenberg-Marquardt approach with 31 to 39 neurons in incremental steps of 2 . The model performance was then compared with existing techniques. Performance results show that the proposed model outperforms basic empirical models. In [46], the relation between the path loss propagation delay and the atmosphere parameter with a neural model is provided. In the work, the neural network model was employed to model the channel propagation in LOS environments. The study also evaluates the accuracy of the model, and it was found that unusual atmospheric conditions are accurately predicted by the model. However, the research was limited to only pressure, temperature, and humidity as the atmosphere parameters, and noise was not considered in the work.

Wu et al. [47] developed a path loss prediction model for railway environments using an artificial neural network model based on the backpropagation network (BPN) architecture. Two datasets were obtained from Viaducts, cuttings and plains at the Zhengzhou-Xi'an express railway line. Base stations were placed every $3 \mathrm{~km}$, transmitting at $930 \mathrm{MHz}$. The ANN predicted model achieved the lowest mean values of $0.6,0.8$, and 0.8 , respectively, which shows that the proposed model is adequate for railway scenarios. A feedforward multilayer perceptron (FLP) was used in [48] to create an ANN for propagation loss prediction in the $900 \mathrm{MHz}$ frequency bands, and the developed model was compared with the ray-tracing algorithm for performance verification. The proposed method demonstrated significant improvements, comparable to analytical models, and revealed faster computation time due to the intrinsic parallelism of an ANN architecture. Neural network parameters were derived in [49] for path loss prediction in a VHF and UHF bands for wireless communications. The authors conducted a field measurement in an urban environment for the purpose of obtaining network information about the losses radio signals transmitted through $189.25 \mathrm{MHz}$ and 479.25 MHz. The obtained network information was used to develop an artificial neural network (ANN) model which was evaluated using the mean squared error (MSE), root mean squared error (RMSE), standard deviation (SD), mean 
TABLE 4: Summary of artificial neural networks contributions.

\begin{tabular}{|c|c|c|}
\hline Authors & Aim & Methods \\
\hline Popescu et al. [35] & $\begin{array}{l}\text { To study the application of neural networks to the prediction of } \\
\text { propagation path loss in urban and suburban environments }\end{array}$ & Feed forward neural networks \\
\hline $\begin{array}{l}\text { Sotiroudis et al. } \\
\text { [36] }\end{array}$ & $\begin{array}{l}\text { To propose an alternative neural network algorithm for the } \\
\text { prediction of propagation path loss in urban environments }\end{array}$ & ANN \\
\hline Oustlin et al. [34] & To analyze ANN models used for macrocell path loss estimation & ANN \\
\hline Kalakh et al. [37] & $\begin{array}{c}\text { To present an ultrawide band propagation channel modeling with } \\
\text { neural networks in a mine environment }\end{array}$ & ANN \\
\hline Zaarour et al. [38] & $\begin{array}{l}\text { To use MLP and RBF artificial neural networks to study ultrawide } \\
\text { band communication channels }\end{array}$ & $\begin{array}{c}\text { ANN: multilayer perception (MLP) and radial } \\
\text { basis function (RBF) }\end{array}$ \\
\hline $\begin{array}{l}\text { Sotiroudis et al. } \\
{[39]}\end{array}$ & $\begin{array}{l}\text { To produce an alternative procedure for predicting propagation } \\
\text { path loss in urban environments }\end{array}$ & $\begin{array}{l}\text { Artificial neural network and application of } \\
\text { adaptive evolutionary algorithms }\end{array}$ \\
\hline Ozdemir et al. [40] & $\begin{array}{l}\text { To use the Levenberg-Marquardt algorithm for studying the } \\
\text { propagation loss of FM radio stations }\end{array}$ & Levenberg-Marquardt algorithm ANN \\
\hline $\begin{array}{l}\text { Dela Cruz and } \\
\text { Caluyo [41] }\end{array}$ & $\begin{array}{c}\text { To develop a statistical path loss model by measuring indoor losses } \\
\text { using a fixed portable indoor antenna }\end{array}$ & ANN \\
\hline $\begin{array}{l}\text { Nadir and Idrees } \\
\text { Ahmad [42] }\end{array}$ & $\begin{array}{c}\text { To address the applicability of the Okumura-Hata model in GSM } \\
\text { frequency band of } 890-960 \mathrm{MHz}\end{array}$ & ANN \\
\hline $\begin{array}{l}\text { Delos Angeles and } \\
\text { Dadios [43] }\end{array}$ & $\begin{array}{c}\text { To predict path loss for TV transmission using alternative neural } \\
\text { networks, and ascertain the proposed model viability }\end{array}$ & ANN \\
\hline Benmus et al. [44] & $\begin{array}{l}\text { To predict the propagation path loss with an empirical model at the } \\
\text { capital city of Libya }\end{array}$ & ANN \\
\hline Ofure et al. [33] & $\begin{array}{l}\text { To use a three-stage approach in the determination of GSM Rx level } \\
\text { from atmospheric parameters }\end{array}$ & ANN \\
\hline Eichie et al. [45] & $\begin{array}{l}\text { To develop an ANN-based path loss estimation model for rural and } \\
\text { urban areas }\end{array}$ & ANN \\
\hline Moazenni [46] & $\begin{array}{l}\text { To study the relation between the path loss propagation delay and } \\
\text { the atmosphere parameter with a neural model }\end{array}$ & ANN \\
\hline $\mathrm{Wu}$ et al. [47] & $\begin{array}{c}\text { To propose a new artificial neural network prediction model for } \\
\text { railway environments }\end{array}$ & ANN \\
\hline
\end{tabular}

absolute error (MAE), and regression coefficient $(R)$. The study reported statistical output of MAE, MSE, RMSE, SD, and $R$ of $0.58 \mathrm{~dB}, 66 \mathrm{~dB}, 0.81 \mathrm{~dB}, 0.56 \mathrm{~dB}$, and 0.99 , respectively. Also, the developed model was compared with known empirical models, and it was observed that the model shows a better performance in prediction, accuracy, and generalization ability. Authors in [50] reported the principle, method, and data expansion methods of machine learning for the purpose of path loss prediction for fifth-generation (5G) mobile networks. Measured data were used to estimate the performance of different propagation models such as the artificial neural network (ANN), support vector regression (SVR), and random forest (RF) alongside the log-distance model. Also, methods on how data expands in order to generate considering amount of training samples for the system were presented. It was shown that the machine learning algorithms exhibit better performance than the logdistance propagation model. However, open research areas to be exploited were also reported. Popoola et al. in [51] conducted a study on the characterization of path loss in the very high frequency (VHF) band exploiting the neural network modeling technique. The article reported how the propagation loss through frequency band $30-300 \mathrm{MHz}$ is characterized based on ANN algorithm and its attributes such as the activation functions and training algorithms based on the measured data at $203.25 \mathrm{MHz}$. The developed model was compared with the widely used empirical models, and it was observed that the ANN developed model outperformed the empirical models based on the statistical analysis results which also recorded a correlation coefficient $(R)$ of 0.95 .

3.3. Evolutionary Computing. Evolutionary computing has also experienced significant attention by researchers within the path loss prediction area, where several works report the use of evolutionary algorithms. For example, reference [52] proposed an alternative procedure to predict propagation path loss in urban environments based on composite differential evolution (CoDE). The model was compared with other popular differential algorithms. The obtained results show that the optimized CoDE-ANN model has higher prediction efficiency that other self-adaptive DE algorithms. Reference [53] proposed the use of a genetic algorithm to estimate the propagation path loss in microcellular systems in the $900 \mathrm{MHz}$ frequency band in three routes in Munich, Germany; Ottawa, Canada; and Rosslyn, USA. The performance of the model was examined using the mean error (ME) and standard deviation (SD) metrics, and findings indicated an error of less than $3 \mathrm{~dB}$ and $7 \mathrm{~dB}$, respectively, for $\mathrm{ME}$ and SD. Even though, the model was limited to only $900 \mathrm{MHz}$ frequency band and distances between 0.1 and $2 \mathrm{~km}$ in urban environments, yet, it provides a better illustration of how the path loss is affected by the area occupied by buildings. Similarly, in [54] a genetic algorithm (GA) path loss models were developed for the prediction of losses for LTE and LTEadvance networks. The GA was used in tuning the Free Space 
TABLE 5: Summary of the evolutionary algorithms' computational process.

\begin{tabular}{|c|c|c|}
\hline Authors & Aim & Methods \\
\hline Sotiroudis et al. [52] & $\begin{array}{c}\text { To make selection of propagation path loss in urban environments an } \\
\text { alternative to procedure prediction }\end{array}$ & $\begin{array}{c}\text { Artificial neural network }+ \text { differential } \\
\text { algorithms. }\end{array}$ \\
\hline $\begin{array}{l}\text { Fernandes and } \\
\text { Soares[53] }\end{array}$ & $\begin{array}{c}\text { To evaluate path loss in microcellular systems at the } 900 \mathrm{MHz} \text { frequency } \\
\text { band }\end{array}$ & Genetic algorithm \\
\hline Cavalcanti et al. [54] & $\begin{array}{c}\text { To carry out a comparative test using the free space and Ericsson } 9999 \\
\text { models along with their optimized version }\end{array}$ & Genetic algorithm. \\
\hline
\end{tabular}

and Ericsson models. Findings from the work revealed resemblance of the models' predictions with the actual measurement data. Table 5 provides the summary of the evolutionary algorithms' computational process.

3.4. Swarm Intelligence. The swarm intelligence expression was introduced in the cellular robotic systems context by Beni and Wang in 1989. Swarm intelligence is the collective behavior of decentralized, self-organized systems, either natural or artificial, typically comprising a population of simple agents or bodies interacting locally with each another and with their environment [55]. Swarm intelligence has also been utilized in various areas in which it has gained attention, including problem forecasting. Swarm intelligence is typically associated to three different algorithms, as categorized in Figure 1. The most widely used, as found from the literature, is particle swarm optimization.

3.4.1. Particle Swarm Optimization. A particle swarm optimization (PSO) algorithm is a population-based quest procedure where the individuals, known as particles, are clustered into a swarm. PSO is a stochastic optimization method that is modeled on the fundamental social behavior of bird flocks, which is then used to solve nonlinear problems [56]. The particle for search in space consists of the personal best vector, position vector $(x)$, and velocity vector $(v)$, and a fitness value. The PSO algorithm can be deployed at the initialization and iteration phases [57]. Each particle is randomly allotted through an $n$-dimensional search space at the initialization phase of the velocity and position vectors, while in iterations each particle looms towards the best solution by modifying its velocity and position in accordance with the equation in [56]. PSO can be applied in various aspects, such as function approximation, optimization of mechanical structures, clustering, and solving systems of equations [8]. Essentially, two different PSO algorithms were developed, namely, the global best PSO (gbest) and the local best PSO (lbest).

3.4.2. Global Best PSO. For the global best PSO, the neighborhood for each particle is the entire swarm. For the star neighborhood topology, the social component of the particle velocity update reflects information obtained from all the particles in the swarm. In this case, the social information is the best position found by the swarm, referred to as $y(t)$.

$$
\begin{aligned}
& v_{i j}(t+1)=v_{i j} t+c_{1} r_{1 j}(t)\left[y_{i j}(t)-x_{i j}(t)\right]+c_{2} r_{2 j}(t)\left[y_{j}(t)-x_{i j}(t)\right], \\
& y_{i}(t+1) \begin{cases}y_{i}(t), & \text { if } f\left(x_{i}(t+1)\right) \geq f\left(y_{i}(t)\right), \\
x_{i}(t+1), & \text { if } f\left(x_{i}(t+1)\right)<f\left(y_{i}(t)\right) .\end{cases}
\end{aligned}
$$

The global best position, $y(t)$, at time step $t$, is defined as

$$
\begin{aligned}
& y(t) \in\left\{y_{0}(t), \ldots, y_{n s}(t)\right\} \mid f(y(t))=\min \left\{f\left(y_{0}(t)\right), \ldots, f\left(y_{n s}(t)\right)\right\} \\
& y(t)=\min \left\{f\left(x_{0}(t)\right), \ldots, f\left(x_{n s}(t)\right)\right\} .
\end{aligned}
$$

\subsubsection{Local Best PSO.}

$$
\begin{aligned}
v_{i j}(t+1) & =v_{i j} t+c_{1} r_{1 j}(t)\left[y_{i j}(t)-x_{i j}(t)\right]+c_{2} r_{2 j}(t)\left[y_{i j}(t)-x_{i j}(t)\right], \\
y_{i}(t+1) & \in\left\{N_{i} \mid f\left(y_{i}(t+1)\right)=\min \{f(x)\}, \quad \forall_{X} \in N_{i}\right\}, \\
N_{i} & =\left\{y_{i-n_{N i}}(t), y_{i-n_{N i}+1}(t), \ldots, y_{i-1}(t), y_{i}(t), y_{i+1}(t), \ldots, y_{i+n_{N i}}(t)\right\} .
\end{aligned}
$$


He et al. in [57] reported the adoption of particle flight path information, which is used by the particle swarm optimization algorithm to train a radial basis function (RBF)-based neural network model in order to create a selfadaptive PSO-RBF NN algorithm for path loss estimation. The performance of the developed model prediction indicated a convergence speed and prediction accuracy better than the traditional RBF neural network. Tahat and Taha [58] applied statistical tuning technique based on particle swarm optimization (PSO) to adjust the COST 231 WalfischIkegami for path loss prediction. The data measurements were carried out to measure the received signal power in a deployed $3 \mathrm{G}$ network at 2.125 GHz FDD mode. The received signal power, roof height, road orientation angle, and buildings separation variables were all considered for the tuning of the COST 231 WI model. The PSO technique was used for the tuning and revealed lowest standard deviation error when compared with measured data. Even though, the work recorded least error, the model was limited to only $2.125 \mathrm{GHz}$ frequency band. Furthermore, in [59], PSO was used to optimize some empirical path loss models for urban outdoor path loss estimation at the $2300 \mathrm{MHz}$ frequency for LTE network systems. Measurement campaign was conducted in the urban areas of Port Harcourt, Nigeria. The modified model was compared with Okumura-Hata, COST 231, Ericsson 999, ECC-33, and Egli models for the specified environments. For the performance metrics, the RMSE and the MAE were used to gauge the models' efficacies. The results obtained were promising with RMSE and MAE values of $3.030 \mathrm{~dB}$ and $0.00162 \mathrm{~dB}$, respectively. Hence, the PSO modified model could be used for the deployment of the long-term evolution (LTE) wireless communication systems in the study locations. In [60], a study of the application of PSO and GA for the path loss estimation in an urban area was presented, where shooting and bouncing ray/ image methods were used to compute the propagation loss for different outdoor environments in a typical commercial area of Taipei. Three different types of antenna arrays were considered, such as $L$ shape, $Y$ shape, and circular shape and used at the base station. The results indicated that PSO demonstrated a better performance than the model developed with a GA.

In the same vein, Reference [61] reported the path loss prediction for mobile phone stations in an outdoor environment in the $900 \mathrm{MHz}$ and $1800 \mathrm{MHz}$ bands. PSO was used for the optimization of the COST 231 Hata model in the prediction of path loss in Irbid city, Jordan. The developed model was compared with the measurements obtained in other locations in Irbid. The results obtained with the proposed model show that the root mean square error (RMSE) amongst the presented and the measured data was enhanced by up to $5 \mathrm{~dB}$ compared with the Hata model and by $29 \mathrm{~dB}$ compared with the Egli model in the $1800 \mathrm{MHz}$ band, for all the environments under the study. Its accuracy was also increased by $25 \mathrm{~dB}$ in the $900 \mathrm{MHz}$ band in comparison with other empirical models.

The hybrid PSO and ANFIS were also used in [16] for path loss prediction for Wi-Fi signal propagation along a passageway. In the methodology of data collection, a Wi-Fi router was used as the transmitter, while a mobile phone as the receiver. The data collected were used as the input variables during the modeling. The performance metrics used to determine the accuracy of the algorithms were SD, MSE, and RMS; these values were compared with reveal the most improved model. The results obtained indicated that the predicted values that were centered on PSO trained ANFIS with a random input were closer to the actual measured values, showing the best prediction results amongst all alternatives tested. The limitation of the study was the random behavior of the received signal. In order to improve the prediction accuracy of the existing empirical models, the PSO was employed in [62] to tune the COST 231 model parameters. Data set was generated through a drive test using a special mobile phone (Huawei U6100), a GPS receiver (NMEA), a receiving antenna, and a laptop installed with test software GENEX Probe. The performance of the tuned model was compared with those of the most widely tested empirical models (SUI, Egli, Hata rural, Hata sub, and COST 231). The root mean square error (RMSE) was used as the performance metric and was calculated for all models present in the study. Findings from the work revealed that the tuned model predictions were better than the other empirical models used. Interestingly, the hybrid PSO-BP-Kriging was employed in [63] to estimate the coverage of the $5 \mathrm{G}$ wireless system. Signal strength propagated from the $5 \mathrm{G}$ base stations was collected and preprocessed by deploying distributed senor nodes, after which the neural network objective function was adjusted by using the variogram function, and the coefficient of the initial weight of the neural network was optimized by applying the enhanced particle swarm optimization algorithm. After the training of the network, it was then used for the interpolation of the untouched blind zones. Both the data obtained from the sensor node and the interpolated estimation outputs were combined to create an effective coverage prediction for the $5 \mathrm{G}$ mobile wireless signal. Simulation results revealed that the proposed algorithm can detect real situations of $5 \mathrm{G}$ mobile network signal coverage more accurately than the other algorithms. It is therefore undeniably that the PSO has also shown great impact in the process of enhancing the prediction accuracy of the empirical path loss propagation models. Table 6 provides summary of past works that employed the PSO during the computational process.

\section{Performance Metrics}

The reviewed works evaluate the performance of applied computational intelligence techniques on path loss prediction by means of statistical measurement metrics. The performance of any model developed for propagation path loss prediction is usually evaluated using several performance metrics, as illustrated in Figure 7. This figure provides a statistical analysis of the different performance metrics used from the survey conducted. It can be observed that the mean square error, root mean squared error, and standard deviation dominate the frequency counts, as many researchers tend to use these metrics to gauge the performance 
TABLE 6: Summary of particle swarm optimization computational process.

\begin{tabular}{|c|c|c|}
\hline Authors & Aims & Methods \\
\hline He et al. [57] & $\begin{array}{c}\text { To design an RBF-based neural network adaptive particle swarm optimization } \\
\text { algorithm }\end{array}$ & PSO + neural network \\
\hline Tahat and Taha [58] & $\begin{array}{c}\text { To propose the application of a statistical tuning technique based on particle } \\
\text { swarm optimization (PSO) to adjust the COST } 231 \text { Walfisch-Ikegami for path } \\
\text { loss prediction }\end{array}$ & PSO \\
\hline Olukunle et al. [59] & $\begin{array}{l}\text { To propose the development of an optimized model for urban outdoor coverage } \\
\text { at } 2300 \mathrm{MHz} \text { frequency for LTE network systems in Port Harcourt urban terrain } \\
\text { roads (Rumuokoro, Eneka and Ikwerre) }\end{array}$ & PSO \\
\hline Chiu et al. [60] & $\begin{array}{l}\text { To evaluate the performance of a particle swarm optimization (PSO) model and a } \\
\text { genetic algorithm (GA) for path loss estimation in an urban area }\end{array}$ & $\mathrm{PSO}+\mathrm{GA}$ \\
\hline $\begin{array}{l}\text { Al Salameh and Al- } \\
\text { Zu'bi [61] }\end{array}$ & $\begin{array}{l}\text { To propose the path loss prediction for mobile phone stations in an outdoor } \\
\text { environment in the } 900 \mathrm{MHz} \text { and } 1800 \mathrm{MHz} \text { bands }\end{array}$ & PSO \\
\hline Omae et al. [16] & $\begin{array}{c}\text { To conduct a study and report the path loss prediction of a Wi-Fi signal } \\
\text { propagation along a passageway using particle swarm optimization (PSO) } \\
\text { trained adaptive neural fuzzy inference system (ANFIS), ANFIS, and PSO } \\
\text { trained with a random input }\end{array}$ & PSO + ANFIS \\
\hline Garah et al. [62] & $\begin{array}{l}\text { To propose the application of particle swarm optimization for the tuning of the } \\
\text { COST } 231 \text { model parameters for the improvement of its accuracy for path loss } \\
\text { prediction }\end{array}$ & PSO \\
\hline $\begin{array}{l}\text { Xiang and Wang } \\
{[63]}\end{array}$ & To report the application of PSO-BP-Kriging for $5 \mathrm{G}$ signal coverage detection & $\begin{array}{c}\text { Enhanced particle swarm } \\
\text { optimization algorithm }\end{array}$ \\
\hline
\end{tabular}

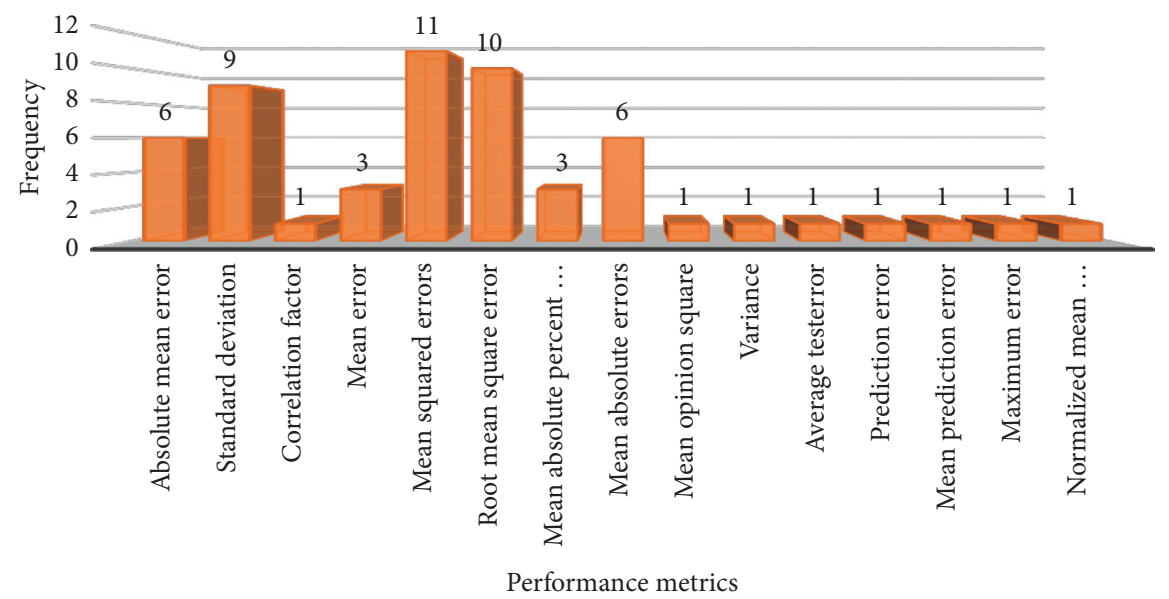

Figure 7: Performance metrics extracted from the survey.

of the models. On contrary, hardly, other statistical metrics such as mean opinion square or average test error were employed as performance metrics.

In Table 7, we provided some research findings obtained using the aforementioned metrics.

\section{Research Trends and General Overview of the Research Area}

This section illustrates the results obtained based on the number of works published in each year ranging from 2004 to 2019, as shown in Figure 8. The trend at which publications have been rolling out in this research area is increasing, as depicted. We can see that the application of CI on path loss prediction has been gaining momentum since
2004. The highest number of publications is witnessed in year 2019, and it is expected to keep increasing because of the attention from researchers wanting to explore the advantages of computational intelligence (CI) techniques. In Figure 9, the percentage ratio of the each taxonomy of the survey is depicted, highlighting researchers attention in all CI techniques. Figure 10 provides the number of articles in each category per year (period 2004-2019).

\section{Open Research Issues and Future Research Direction}

Despite the improvement recorded by the various CI algorithms, there are open research problems. The research problems are discussed in this section, and new directions 
TABLE 7: Comparison of some review literatures.

\begin{tabular}{llcc}
\hline Authors & Year & Methods & Performance \\
\hline Oustlin et al. [34] & 2010 & ANN & ME 0 dB \\
Salman et al. [25] & 2017 & Fuzzy & RMSE 5.23 dB \\
Ozdemir et al. [40] & 2014 & ANN & RMSE 9.57 dB \\
Olukunle et al. [59] & 2017 & SWARM & RMSE 3.030 dB \\
Danladi and Vasira [28] & 2018 & Fuzzy & MAE 1.55 dB \& 0.4 dB \\
Al Salameh and Al-Zu'bi [61] & 2014 & SWARM & RMSE 5dB \\
Fernandes and Soares [53] & 2014 & Evolutionary $3 \mathrm{~dB}$ \\
Surajudeen-Bakinde et al. [27] & 2018 & Fuzzy & RMSE 4.47 dB \\
Popoola et al. [49] & 2019 & ANN & RMSE 0.81 dB \\
Popoola et al. [51] & 2019 & ANN & R 0.95 \\
\hline
\end{tabular}

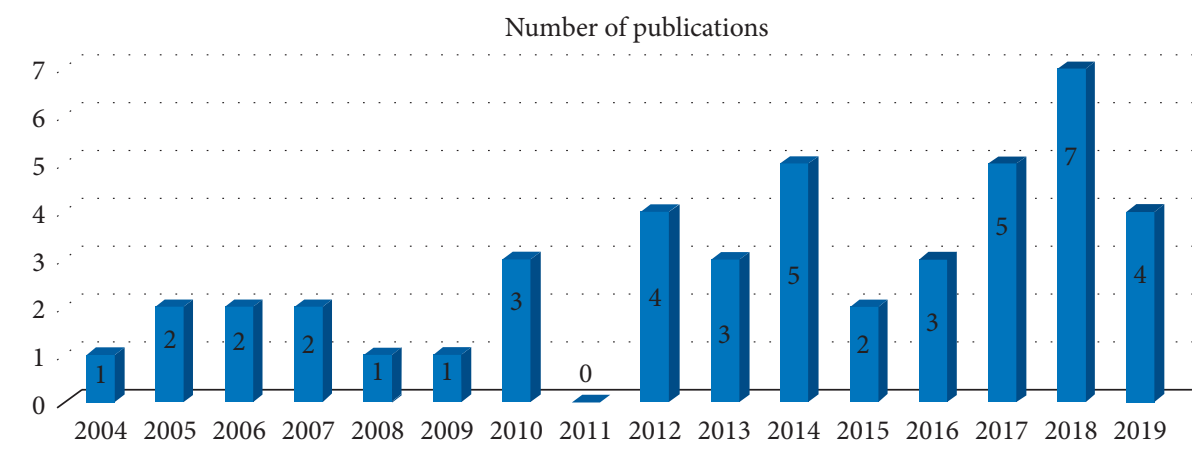

Figure 8: Trend of publications.

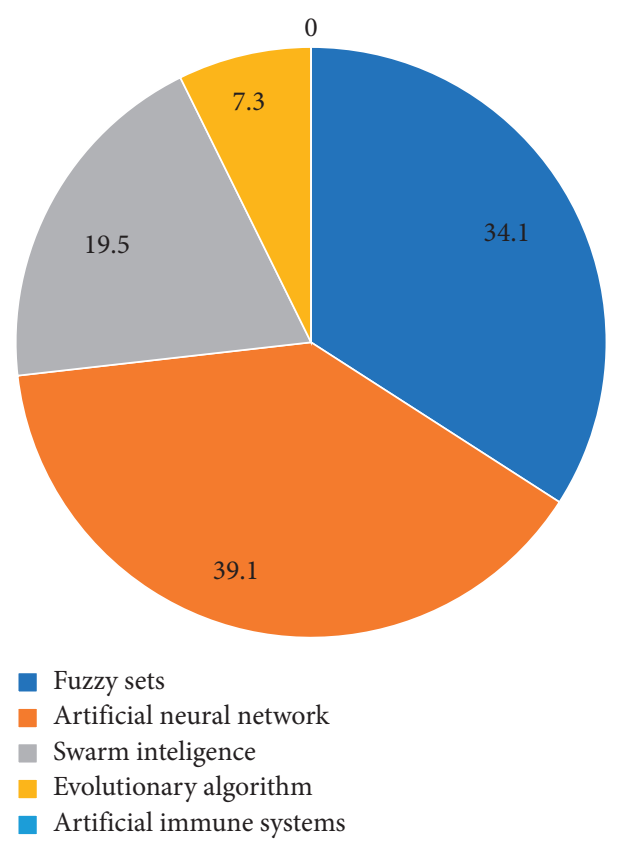

FIgURE 9: Percentage of papers in each category.

are pointed out to provide research opportunities for developing research in propagation path loss prediction.

6.1. Application of Deep Learning. Deep learning is the new generation of the ANN which is currently attracting tremendous attention from the research community. However, surprisingly the deep learning remains unexploited in propagation path loss prediction notwithstanding it is effectiveness, efficiency, and robustness in solving real world problems. Empirical evidence from the literature has proven that the deep learning architectures such as the deep 


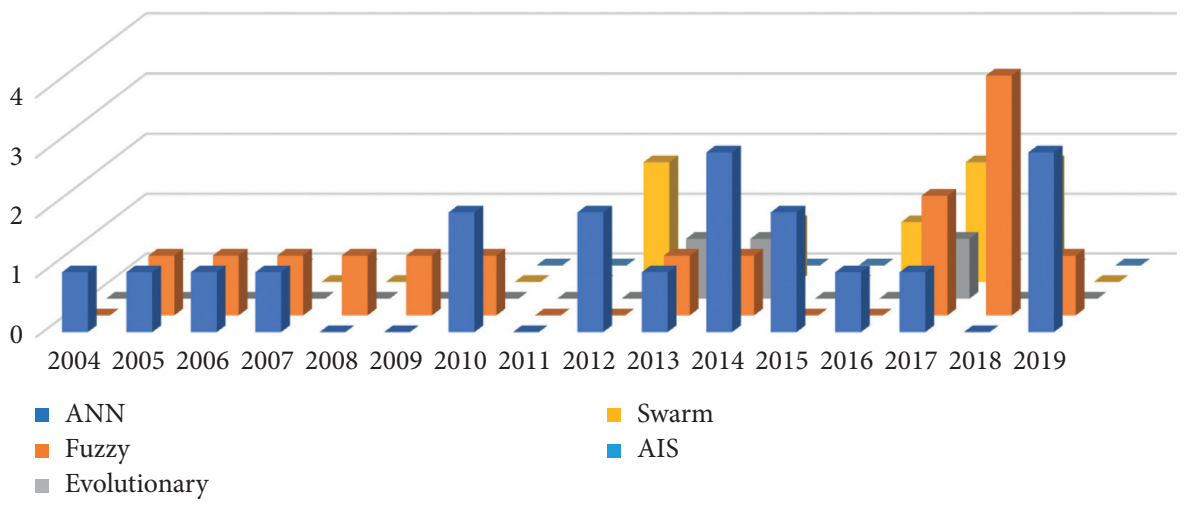

FIgURE 10: Number of articles in each category per year (period 2004-2019).

belief network, convolutional neural network, attentive deep neural network, stack autoencoder, generative adversarial network, deep reinforcement learning, deep long short-term memory, and deep recurrent neural network among many others can handle machine learning problems such as prediction, clustering, and classification better than the shallow ANN currently in use for propagation path loss prediction especially when the amount of the data size is large. As such, this survey suggests researchers to explore these architectures of the new generation ANN in the domain of propagation path loss.

6.2. Multiterrain Model. Observations from the survey pointed out that the propagation path loss prediction is mainly conducted for a single terrain. Therefore, the model developed based on any CI algorithm for a particular terrain is limited for prediction of path loss within the terrain. The result obtained from such model cannot be generalized to other terrains. The multiterrain propagation path loss prediction model remains an open issue. We suggest researchers to apply deep learning architecture because of its ability to handle large scale data to investigate the possibility of propagation path loss prediction for multiple terrains.

6.3. Unexploitation of Physical Algorithms. It has been observed from the survey that physical algorithms that derived their inspiration from the mechanism and processes of physical systems remain unexploited in propagation path loss prediction. Example of such algorithms includes simulated annealing, harmony search, memetic algorithm, and cultural algorithm. This is despite the fact that these classes of algorithms have been applied in other domain to solve real world problems and found to be effective and efficient. Therefore, we enjoin the research community to explore the physical algorithms in the area of propagation path loss prediction and compare the performance with the classical algorithms from evolutionary and swarm computation.

6.4. Nature-Inspired Algorithms and Deep Learning. It was observed from the survey that the deep learning architecture that its hyperparameters were optimized by the global optimization algorithm from the family of evolutional and swarm computation remains unexploited in propagation path loss prediction. Empirical works have shown that the deep learning architecture hyperparameters optimized by the global optimization algorithm are more effective than the conventional architecture. It will be interesting to investigate the performance of deep learning architecture that its hyperparameters are optimized by the global optimization algorithm in the domain of propagation path loss.

6.5. Shallow ANN. It is clearly shown from the survey that researchers in this domain heavily relied on the shallow ANN for propagation path loss prediction. The shallow ANN has limitation in handling large scale data because the performance of the shallow ANN diminishes as the amount of data increases. In addition, unlike the new generation ANN-deep learning, the shallow ANN require manual data engineering to perform feature extraction on the data before feeding into the shallow ANN for propagation path loss prediction. To eliminate this tedious procedure and waste of time and resources, we suggest the application of the deep learning architecture.

6.6. Immune Algorithms. The application of immume algorithms in propagation path loss prediction remains unexploited. The category of algorithms derived their inspiration from the complex adaptive biological immune system. Example of such algorithms includes negative selection, clonal selection, artificial immune systems, and immune network models. It was found from the literature search that immune algorithms are yet to gain attention from researchers for propagation path loss prediction in different environments. On the other hand, studies conducted on immune system reveal that it has more applications in data communication networks, such areas as pattern recognition, data clustering, security, anomaly, and web mining, among many others [9]. Therefore, we suggest researchers to explore the immune algorithms in propagation path loss prediction. It is imperative to discover the opportunity of applying these classes of algorithms for propagation path loss prediction.

6.7. Under-Exploitation of the CI. Not all the CI techniques have been thoroughly studied, as shown in Figure 9. Figure 9 
highlights evolutionary algorithms that need more research on propagation path loss for various environments.

6.8. Hybrid Approaches. The combination of CI and existing empirical or deterministic path loss propagation models may provide trade-off between ease of application and accuracy. The empirical path loss models are dependent on the local terrain and have high prediction error when applied to another terrain. The deterministic path loss prediction models are dependent on the modeling of the terrain, buildings, and the position of the antennas, which require updated and comprehensive terrain databases that are usually not cost effective. Therefore, the implementation of combination of empirical/deterministic models and CI techniques would successfully aid at better predicting with little or no errors. This is another open research area that needs to be looked upon.

\section{Conclusion}

This study presents a systematic literature review on the application of computational intelligence techniques for the prediction of path losses for different environments and spanning different operating frequencies. The literature review covered different classes of CI techniques as follows: fuzzy sets, artificial neural networks (ANNs), evolutionary algorithms, swarm intelligence (SI), and artificial immune systems (AISs). The current status on the application of CI techniques for path loss prediction, research trends in the past few years, and open research problems and future research areas and expectations are outlined in the paper. It was discovered that the efforts made by researchers to propose a better model for the prediction of path loss in different terrains has at times led to the testing and simultaneous application of two different CI techniques in a specific environment. The comprehensive review presented in this paper can thus become a first point of reference for new researchers interested in radio propagation and channel modeling. Also, expert researchers in channel modeling or radio propagation can use this review to gain further insight when suggesting a novel approach for path loss prediction.

\section{Data Availability}

No data were used to support the findings of this study.

\section{Conflicts of Interest}

The authors declare that they have no conflicts of interest.

\section{Acknowledgments}

This work was funded by the Federal Ministry of Education, Federal Government of Nigeria, Tertiary Education Trust Fund (TETFUND), Institutional Based Research (IBR) Fund, 2018.

\section{References}

[1] B. Omar, M. A.-Z. Muneer, and M. S. Al Salameh, "Hata path loss model tuning for cellular networks in Irbid city," in Proceedings of the 2015 International Conference on Computer and Information Technology: Ubiquitous Computing and Communications:Dependable, Automatic and Secure Computing: Pervasive Intelligence and Computing, Liverpool, UK, 2015.

[2] J. D. Parsons, The Mobile Radio Propagation Channel, John Wiley \& Sons, Hoboken, NJ, USA, 2nd edition, 2000.

[3] I. Joseph and C. C. Konyeha, "Urban area path loss propagation prediction and optimization using Hata model at $800 \mathrm{MHz}$," IOSR Journal of Applied Physics, vol. 3, no. 4, pp. 8-18, 2013.

[4] N. Faruk, Y. A. Adeniran, and A. A. Ayeni, "Error bounds of empirical path loss models on VHF/UHF bands in Kwara state," in Proceedings of the 2013 EUROCON, Zagreb, Croatia, 2013.

[5] A. Hojjat and S. Nazmul, Computational Intelligence Synergies of Fuzzy Logic, Neural Networks and Evolutionary Computing, John Wiley \& Sons, Hoboken, NJ, USA, 1st edition, 2013.

[6] R. Kulkarni, A. Förster, and G. K. Venayagamoorthy, "Computational intelligence in wireless sensor networks: a survey," IEEE Communications Surveys \& Tutorials, vol. 13, no. $1,2011$.

[7] B. Kitchenham, O. Pearl Brereton, D. Budgen, M. Turner, J. Bailey, and S. Linkman, "Systematic literature reviews in software engineering - a systematic literature review," Information and Software Technology, vol. 51, no. 1, pp. 7-15, 2009.

[8] A. P. Engelbrecht, "Computational intelligence," 2007, http:// www.matlabsite.com.

[9] A. Abbas, L. Zhang, and S. U. Zhang, "A survey on contextaware recommender systems based on computational intelligence techniques," Computing, vol. 97, pp. 667-690, 2015.

[10] L. A. Zadeh, "Fuzzy sets notes," Information and Control, vol. 8, pp. 338-353, 1965.

[11] K. Hirota, Industrial Applications of Fuzzy Technology, World Scientific, Tokyo, Japan, 1993.

[12] T. Terano, K. Asai, and M. Sugeno, Fuzzy SyetemsAcademic Press Profession, Cambridge, MA, USA, 1994.

[13] M. Jezewski and P. Prokopowicz, "Theory and applications of ordered fuzzy numbers," Studies in Fuzziness and Soft Computing, Springer, Berlin, Germany, 2017.

[14] E. Czogala and J. Leski, Fuzzy and Neuro-Fuzzy Intelligent SystemsPhysica-Verlag, Heidelberg, Germany, 2000.

[15] J. Leski, Neuro-Fuzzy Systems, WNT, Warsaw, Poland, 2008.

[16] M. O. Omae, E. N. Ndungu, and P. L. Kibet, "Comparing the performance of ANFIS, PSO-ANFIS and PSO-ANFIS with random input in indoor Wi-Fi signal propagation prediction," in Proceedings of the 2014 Sustainable Research and Innovation Conference, Nairobi, Kenya, 2014.

[17] R. DasMahapatra, "Optimal power control for cognitive radio in spectrum distribution using ANFIS," in Proceedings of the 2015 IEEE International Conference on Signal Processing, Informatics, Communication and Energy Systems (SPICES), Kozhikode, India, 2015.

[18] T. E. Dalkili, B. Y. Hanci, and A. Apaydin, "Fuzzy adaptive neural network approach to path loss prediction in urban areas at GSM-900 band," Turkey Journal Electrical \& Computer Science, vol. 18, pp. 1077-1094, 2010.

[19] P. Supachai, P. Pisit, and S. Suripon, "Muti-layer fuzzy logic sets for mobile path loss in forests," in Proceedings of the 
TENCON 2006-2006 IEEE Region 10 Conference, Hong Kong, China, 2006.

[20] A. Gupta, S. C. Sharma, S. Vijay, and G. Vishal, "Secure path loss prediction using fuzzy logic approach," in Proceedings of the 2008 4th International Conference on Wireless Communication and Sensor Networks, Indore, India, 2008.

[21] M. Sanu, K. Shylaja, T. Jayasri, and M. Hemalatha, "Path loss prediction in wireless communication system using fuzzy logic," Indian Journal of Science and Technology, vol. 7, pp. 642-647, 2014.

[22] J. Sumit, S. M. Govind, and K. Chandra, "Path loss correction for signal propagation amongst low roof top buildings using fuzzy logic," International Journal of Computer Applications, vol. 83, 2013.

[23] W. Bhupuak and S. Tooprakai, "Minimizing path loss prediction error using $\mathrm{k}$ means clustering and fuzzy logic," Turkish Journal of Electrical Engineering \& Computer Science, vol. 26, 2018.

[24] P. Supachai and P. Pisit, "Statistic microwave path loss modeling in urban line-of-sight area using fuzzy linear regression," in Proceedings of the 2005 ICCAS, Suwon-Si, Republic of Korea, 2005.

[25] M. A. Salman, S. I. Popoola, N. Faruk, N. T. SurajudeenBakinde, A. A. Oloyede, and L. A. Olawoyin, "Adaptive neuro-fuzzy model for path loss prediction in the VHF band," in Proceedings of the 2017 Conference on Computing, Networking and Informatics, Ota, Nigeria, 2017.

[26] M. J. Jafri, J. Ely, and L. Vahala, "Interference path loss prediction in A319/320 Airplanes using modulated fuzzy logic and neural networks," in Proceedings of the 2007 Fuzzy Information Processing Society, 2007. Annual Meeting of the North American, San Diego, CA, USA, 2007.

[27] N. T. Surajudeen-Bakinde, N. Faruk, S. I. Popoola et al., "Path loss predictions for multi-transmitter radio propagation in VHF bands using adaptive neuro-fuzzy inference system," Engineering Science and Technology, an International Journal, vol. 21, no. 4, pp. 679-691, 2018.

[28] A. Danladi and P. G. Vasira, "Path loss modeling for next generation wireless network using fuzzy logic-spline interpolation technique," Journal of Engineering Research and Reports, 2018.

[29] O. O. Shoewu, M. A. Adedoyin, L. A. Akinyemi, and L. I. Oborkhale, "Fuzzy-logic based path loss models for Metropolitan environment," in Proceedings of the 2018 IEEE International Workshop on Signal Processing Systems (SiPS), Cape Town, South Africa, 2018.

[30] N. Faruk, Y. A. Adeniran, and A. A. Ayeni, "Error bounds of empirical path loss models on VHF/UHF bands in Kwara state," in Proceedings of the 2019 EUROCON, Ilorin, Nigeria, 2019.

[31] W. S. McCulloch and P. Walter, "A logical calculus of the ideas immanent in nervous activity," The Bulletin of Mathematical Biophysics, vol. 5, pp. 115-133, 1943.

[32] "History of artificial intelligence," 2018, https://en.wikipedia. or/wiki/history_of_artificial_intelligence.

[33] J. E. Ofure, O. O. David, A. M. Oludare, and A. A. Musa, "Artificial neural network model for the determination of GSM Rxleve from atmospheric parameters," Engineering Science and Technology: An International Journal, 2016.

[34] E. Oustlin, H.-J. Zepernick, and H. Suzuki, "Macrocell pathloss prediction using artificial nueral network," IEEE Transactions on Vehicular Technology, vol. 59, pp. 2735-2747, 2010.

[35] I. Popescu, I. Nafornita, and P. Constantinou, "Comparison of neural network models for path loss prediction," in
Proceedings of the IEEE International Conference on Wireless And Mobile Computing, Networking And Communications, Montreal, Canada, 2005.

[36] S. P. Sotiroudis, K. Siakavara, and J. N. Sahalos, "A neural network approach to the prediction of the propagation path loss for mobile communications sysytems in urban envinronments," in Proceedings of the IEEE International Conference on PIERS Proceedings, Prague, Czech Pepubilc, 2007.

[37] M. Kalakh, K. Kandil, and N. Hakem, "Neural networks model of an UWB channel path loss in a mine environment," in Proceedings of the 2012 IEEE 75th Vehicular Technology Conference, Yokohama, Japan, 2012.

[38] N. Zaarour, N. Kandil, N. Hakem, and C. Despins, "Comparative experimental study on modeling the path loss of an UWB channel in a mine environment using MLP and RBF neural networks," in Proceedings of the 2012 International Conference on Wireless Communications in Underground and Confined Areas, Clermont Ferrand, France, 2012.

[39] S. P. Sotiroudis, S. K. Goudos, K. A. Gotsis, K. Siakavara, and J. N. Sahalos, "Application of a composite differential evolution algorithm in optimal neural network design for propagation path-loss prediction in mobile communication systems," IEEE Antennas and Wireless Propagation Letters, vol. 12, pp. 364-367, 2013.

[40] A. R. Ozdemir, M. Alkan, M. Kabak, M. Gulsen, and M. H. Sazli, "The prediction of propagation loss of FM radio station using artificial neural network," Journal of Electromagnetic Analysis and Applications, vol. 06, no. 11, pp. 358365,2014

[41] J. C. Dela Cruz and F. S. Caluyo, "Heuristic modelling of path loss inside residences at $677 \mathrm{MHz}$," in Proceedings of the 7th IEEE International Conference Humanoid, Nanotechnology, Information Technology, Palawan, Philippines, 2014.

[42] Z. Nadir and M. Idrees Ahmad, "RF coverage and pathloss forecast using neural network," Advances in Systems Science, pp. $275-384,2014$.

[43] J. C. Delos Angeles and E. P. Dadios, "Neural network-based path loss prediction for digital TV macrocells," in Proceedings of the 8th IEEE Interational Conference Humanoid, Nanotechnology, Information Technology, Cebu, Philippines, 2015.

[44] T. A. Benmus, R. Abboud, and M. K. Shater, "Neural network approach to model the propagation path loss for great Tripoli area at 900, 1800, and $2100 \mathrm{MHz}$ bands," in Proceedings of the 16th International Conference on Sciences and Techniques of Automatic Control \& Computer Engineering, Monastir, Tunisia, 2015.

[45] J. O. Eichie, O. D. Oyedum, M. O. Ajewole, and A. M. Aibinu, "Comparative analysis of basic models and artificial neural network based model for path loss prediction," Progress in Electromagnetics Research, vol. 61, pp. 133-146, 2017.

[46] T. Moazenni, "A wireless propagation channel model with meteorological quantities using neural networks," in Proceedings of the 2006 IEEE GCC Conference (GCC), Manama, Bahrain, 2006.

[47] D. Wu, G. Zhu, and B. Ai, "Application of artificial neural networks for path loss prediction in railway environments," in Proceedings of the 2010 5th International ICST Conference on Communications and Networking in China, Beijing, China, 2010.

[48] G. Cerri, M. Cinalli, F. Michetti, and P. Russo, "Feed forward neural networks for path loss prediction in urban environment," IEEE Transactions on Antennas and Propagation, vol. 52, no. 11, 2004. 
[49] S. I. Popoola, A. Jefia, A. A. Atayero et al., "Determination of neural network parameters for path loss prediction in very high frequency wireless channel," IEEE Access, vol. 7, pp. 150462-150483, 2019.

[50] Y. Zhang, J. Wen, G. Yang, Z. He, and J. Wang, "Path loss prediction based on machine learning: principle, method, and data expansion," Applied Sciences, vol. 9, no. 9, p. 1908, 2019.

[51] S. I. Popoola, N. Faruk, N. T. Surajudeen-Bakinde, A. A. Oloyede, A. A. Atayero, and L. A. Olawoyin, "Characterization of path loss in the VHF band using neural network modeling technique," in Proceedings of the 2019 19th International Conference on Computational Science and Its Applications (ICCSA), Saint Petersburg, Russia, 2019.

[52] S. P. Sotiroudis, S. K. Goudus, K. A. Gotsis, K. Siakarva, and J. N. Sahalos, "Optimal artifcial neural network design for propagation path-loss prediction using adaptive evolutionary algorithms," in Proceedings of the 2013 7th European Conference on Antennas and Propagation (EuCAP), Gothenburg, Sweden, 2013.

[53] L. C. Fernandes and A. J. M. Soares, "Path loss prediction in microcellular environments at $900 \mathrm{MHz}$," AEU-International Journal of Electronics and Communications, vol. 68, no. 10, pp. 983-989, 2014.

[54] B. J. Cavalcanti, A. G. d'Assunção, and L. M. Mendon, "Optimizing empirical propagation models for LTE and LTEA using genetic algorithms at $879 \mathrm{MHz}$," in Proceedings of the 2017 IEEE-APS Topical Conference on Antennas and Propagation in Wireless Communications (APWC), Verona, Italy, 2017, https://ieeexplore.ieee.org/author/37531408200.

[55] G. Beni and J. Wang, "Swarm intelligence in cellular robotic syetems," in Proceedings of the NATO Advanced Workshop on Robots and Biological Systems, Florence, Italy, 1989.

[56] W. Duch, What is Computational Intelligence and Where is it Going?, Department of Informatics Nicolaus Corpenicus University and School of Computer Engineering Nanyang Technological University, Singapore, 2007.

[57] T. He, D. Tangren, W. Yong, L. H. X. Chen, and G. Qin, "Particle swarm optimization RBF neural network model for internet traffic prediction," in Proceedings of the 2016 International Conference on Intelligent Transportation, Big Data \& Smart City, Changsha, China, 2016.

[58] A. Tahat and M. Taha, "Statistical tuning of Walfisch-Ikegami propagation model using particle swarm optimization," in Proceedings of the 2012 19th IEEE Symposium on Communications and Vehicular Technology in the Benelux (SCVT), Eindhoven, Netherlands, 2012.

[59] A. A. Olukunle, N. C. Onyebuchi, A. K. Cosmos, and O. C. Reginald, "Implementation of particle swarm optimization technique for enhanced outdoor network coverage in long term evolution network in Port Harcourt Nigeria," European Journal of Engineering Research and Science, vol. 2, 2017.

[60] C. C. Chiu, Y. T. Cheng, and C. W. Chang, "Comparison of particle swarm optimization and genetic algorithm for the path loss reduction in an urban area," Journal of Applied Science and Engineering, vol. 15, 2012.

[61] M. S. H. Al Salameh and M. M. Al-Zu'bi, "Measurements and path loss models for cellular communications in Jordan," International Journal of Networking and Communication, 2014.

[62] M. Garah, H. Oudira, L. Djouane, and N. Hamdiken, "Particle swarm optimization for the path loss reduction in suburban and rural area," International Journal of Electrical and
Computer Engineering (IJECE), vol. 7, no. 4, pp. 2125-2131, 2017.

[63] T. Xiang and H. Wang, "Research on distributed 5G signal coverage detection algorithm based on PSO-BP-kriging," Sensors, vol. 18, no. 12, 2018. 